\title{
Productization and product structure enabling BIM implementation in construction
}

\section{Productization and product structure}

\author{
Solmaz Mansoori, Janne Harkonen and Harri Haapasalo \\ Industrial Engineering and Management, University of Oulu, \\ Oulu, Finland
}

Received 30 September 2021 Revised 27 December 2021 Accepted 20 January 2022

\begin{abstract}
Purpose - This study aims to facilitate consistency of information in building information modelling (BIM) and address the current BIM gaps through the perspectives of the productization concept and product structure (PS).

Design/methodology/approach - The study follows a conceptual research approach in conjunction with a single case study. First, the previous studies on BIM implementation, productization and PS are reviewed. Further, a case study is used to analyse the current state of productization in the construction sector and develop a functional PS for construction.

Findings - A Part-Phase-Elements Matrix is proposed as a construction-specific PS to facilitate consistency in information and to enhance BIM. The proposed matrix provides new avenues to facilitate consistent information exchange through the interconnection between conceptual PS and standard building objects library, and encourage collaborative communication between stakeholders.

Originality/value - This study explores the core of the productization concept and PS as means to facilitate consistency of information and thus address the current gaps in BIM. This as building projects progressively move towards systematic modular and prefabricated construction where the flow of reliable information about product and construction offerings becomes increasingly important.
\end{abstract}

Keywords Productization, Product structure, Information management, BIM, Construction management Paper type Research paper

\section{Introduction}

The construction industry is fragmented and complex with only modest productivity development (Boton et al., 2016). The industry is inherently a loosely coupled system in which it is difficult to develop components and systems that are suited to the situations at specific sites because of a lack of clarity in specifications, lack of consistency and the unpredictably changing environment (Dubois and Gadde, 2002, p. 622). There are challenges specifically concerning the collaborative side of activities.

Building information modelling (BIM) is expected to support the digitisation of construction and improve interoperability via structuring and managing design information (Eastman and Siabiris, 1995; Torregrosa-Jaime et al., 2018). BIM promotes a common environment for all information defining a building with its common parts and activities (RICS, 2015). However, BIM has remained ineffective in practice (Azhar, 2011; Cao et al., 2015) and many challenges rooted in processes, technology and people-related issues prevent BIM implementation (Eastman et al., 2008; Ma et al., 2020). Despite continued global standardisation efforts to assist BIM implementation, existing standards have some shortcomings in delivering their advantages, and BIM implementation suffers as a result of

(C) Solmaz Mansoori, Janne Harkonen and Harri Haapasalo. Published by Emerald Publishing Limited. This article is published under the Creative Commons Attribution (CC BY 4.0) licence. Anyone may reproduce, distribute, translate and create derivative works of this article (for both commercial and noncommercial purposes), subject to full attribution to the original publication and authors. The full terms of this licence may be seen at http://creativecommons.org/licences/by/4.0/legalcode

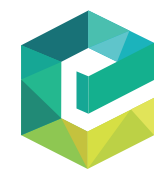

Engineering, Construction and Architectural Management

Emerald Publishing Limited DOI 10.1108/ECAM-09-2021-0848 
their inefficient application (Aram and Eastman, 2013; Patacas et al., 2015), poor interoperability (Marzouk and Othman, 2020; Meng et al., 2020; Stoyanova, 2020) with other enterprise systems like Geographic Information Systems (GIS), enterprise resource planning (ERP) and product lifecycle management (PLM) (Aram and Eastman, 2013; Marzouk and Othman, 2020; Stoyanova, 2020); insufficient compatibility of BIM and consistency with the needs, values and competencies of the potential adopter (Shirowzhan et al., 2020; Son et al., 2015); unreliable data exchange (McGraw-Hill Construction, 2012); and data ownership issues (Ghaffarianhoseini et al., 2017). Despite recent high-tech field data acquisition systems that enable efficient access to building data (Park et al., 2021), their integration into the BIM process to enable information flow throughout the construction phases is complicated (Jia et al., 2022; Schiavi et al., 2022). BIM necessitates to be enhanced to allow consistent handling of data and to improve system integration.

Construction projects are divided into phases with their own sets of data requirements. Versatile stakeholders and suppliers use a variety of systems (Bryde et al., 2013) where information loss and data corruption are inevitable. Current BIM modelling often includes a restricted set of building component data, mainly created during the design process and data are currently collected in discrete information silos isolated and stored in different places and formats (Costa and Madrazo, 2015). Thus, many construction firms operate in silos rather than encouraging a more collaborative culture (Neff et al., 2010; Oraee et al., 2019). Consequently, stakeholders and systems are not integrated and many of the key advantages of collaborative BIM use remain unexplored, while it is emphasised that BIM's value lies in collaborating and optimising the information flow across project lifecycles (Eadie et al., 2013; Razali et al., 2019). To achieve the stated benefits, BIM requires the right type of data at the right time for use by all stakeholders throughout the lifecycle of a construction project.

Although several BIM guidelines have been published, comprehensive plans for data use are lacking throughout the project lifecycle and stakeholders lack access to the information required to run the BIM efficiently (Halttula, 2020). Construction is a multidisciplinary industry with groups of professionals who use distinct terminologies (Handford and Koester, 2019), which makes information communication challenging. As a result, a consistent data interchange mechanism is required.

Learning from discrete manufacturing experiences is a valuable way to increase construction industry efficiency (Bajjou and Chafi, 2020; Jupp, 2016) and achieve concurrent construction by advanced BIM (Luo et al., 2020; Succar, 2010). This as the current situation in construction is quite similar to that experienced by complex manufacturing some decades ago (Jupp and Nepal, 2014). We attempt to address these gaps inspired by methods that have been effectively implemented in manufacturing. Product Structure (PS) and productization principles look very promising avenues with good potential to enable an information-centric management approach to design and construction, enabled by BIM.

A well-designed transactional framework and concrete integration strategies, together with information exchange between project parties play a crucial role in successful BIM implementation and productivity improvement (Azhar, 2011; Heravi et al., 2019; Radl and Kaiser, 2019). PS as a structured product information repository is seen as the missing link between the BIM approach, disconnected construction processes and IT (Boton et al., 2018; Harkonen et al., 2018; Holzer, 2014). PS is a structural representation of a product, giving the outline for linking to product's information and the backbone data, which provides a core entity for transmitting crucial information among collaborative enterprises (Boton et al., 2018; Liang et al., 2010); it enables platform-based production and strengthens stakeholder engagement and cooperation from product development to marketing (Gunzenhauser and Bongulielmi, 2007; Küchenhof and Krause, 2020). In other words, PS bridges the development and the offering of new products (Harkonen et al., 2015; Simula et al., 2008). The product structure allows different types of products to be productized via a similar 
logic (Lahtinen et al., 2021). PS will enable the consistent handling of data, allow transactions, enable trust in data, and supports system integration, something not supported by current BIM.

Productization is the systematisation of the product description, and PS is one method of doing so. The productization concept originated from managerial texts mainly used in service and software industries (Valminen and Toivonen, 2012). Productization is defined as the process of converting ad hoc offerings into well-defined products using a systematic approach (Wirtz et al., 2021). Productization also refers to the commercial and technical modelling of the offerings according to a consistent PS (Harkonen et al., 2017). Productization and PS with effective production management show promising potential to consider construction offering and improve the BIM efficiency.

Productization and PS are successful practices in the manufacturing industry, which differ from the nature of the construction industry. Building on recent developments in the research on the role of PS in improving BIM, and consequently PLM-ERP integration (Boton et al., 2018; Harkonen et al., 2018, 2019a; Holzer, 2014), this study proposes a PS applicable to the construction context as already called for by Aram and Eastman (2013) and Babič et al. (2010). This study looks into the potential of PS and the barriers to productization and BIM implementation while keeping in mind the fundamental characteristics of construction projects. We propose a conceptual framework for PS. It is expected that the proposed PS will integrate and share trustworthy information from all construction phases systematically and consistently. The proposed PS addresses the collaborative use, something that a traditional PS may not acknowledge enough.

The framework is developed in two stages; First, a general PS is enhanced with a predefined building object library that allows for consistent data handling and can be interpreted equally well by stakeholders with various professional backgrounds. This is followed by considering collaborative stakeholder engagement as a crucial issue in successful BIM implementation. This is addressed by demonstrating the relation between product parts, building elements and users, to facilitate the integration of stakeholders and systems. Hence, we propose a literature review-based framework that, when coupled with research into productization and BIM challenges, results in a practical and effective PS for the construction setting. The above discussion can be framed into the following research questions (RQs):

$R Q 1$. How do the cornerstones of productization and product structure promote information consistency and address current gaps in BIM implementation in the construction context?

RQ2. What are current productization challenges in the construction context and how can the existing gaps in BIM implementation be addressed?

RQ3. How can a specific PS be formed to support productization and BIM implementation by enabling reliable information sharing between different stakeholders?

This qualitative study is realised as a combination of conceptual research and a single case study to collect data and review the state of the art of productization, PS and BIM implementation gaps to shed light on how productization and PS concepts can potentially support BIM.

The article proceeds as follows: we first review the literature on BIM, productization and product structure in Section 2 to highlight the potential of productization and product structure to address challenges of successful BIM implementation. The above-mentioned concepts are combined in the literature synthesis to offer foundations for a PS framework. The research process and applied methodology are outlined in Section 3. Based on literature results and empirical data, we propose a new conceptualisation for PS on both a general and construction applicable level. The framework's potential practical applicability is then
Productization and product structure 
discussed, with a focus on its contribution to successful BIM deployment (Section 4). We conclude by outlining some key results and directions for future studies in Section 6 .

\section{Literature review}

\subsection{Challenges and gaps in BIM implementation}

"BIM as a powerful but complex technology" (Kaner et al., 2008, p. 321), is assumed to be a solution to the inefficiencies in the construction industry (Terreno et al., 2019; Zuppa et al., 2009). Using BIM as an object-oriented design tool can enhance component production consistency (Wen et al., 2021) and productivity (Durdyev et al., 2021; Eastman et al., 2008). The promise involves new opportunities by enhancing information exchange and knowledge management (Antwi-Afari et al., 2018) and improving executive efficiency (Eadie et al., 2013).

BIM digitally expresses the physical and functional characteristics of construction processes and the offering but has still many challenges hindering the implementation: Issues with information interoperability (Pauwels et al., 2017), lack of defined standards and technical integration requirements (Eastman et al., 2008; Gerges et al., 2017; Sun et al., 2017), data ownership, information quality, technical interfaces, data entry accuracy and sharing of data (Azhar, 2011; Olanrewaju et al., 2020) are some of the technical and process-related challenges. People-related challenges rooted in the lack of experience among project teams and external organisations (Bryde et al., 2013; Eadie et al., 2013; NBS, 2016), the need for responsibility in the distribution of operational development, identifying suitable times for stakeholder engagement (Azhar, 2011), employees refusing to learn (Bryde et al., 2013; Gardezi et al., 2014) and cultural resistance (Eadie et al., 2013; Olanrewaju et al., 2020).

The challenges call for a well-designed transactional structure and guidelines for information integration and exchange among involved parties (Azhar, 2011; Gerges et al., 2017), and interoperability with other enterprise systems (Ghaffarianhoseini et al., 2017; McGraw-Hill Construction, 2012; Sun et al., 2017) like Geographic Information Systems (GIS), enterprise resource planning (ERP) and product lifecycle management (PLM) (Aram and Eastman, 2013; Marzouk and Othman, 2020; Stoyanova, 2020). It is widely understood how the collaboration of multidisciplinary and geographically separate project members through continuous, reliable and real-time information exchange plays a key role in conflict resolution and keeping projects on schedule and budget (Becerik-Gerber and Rice, 2010; Tang et al., 2020). As evidenced, a common data environment as a standardised information exchange platform facilitates project-wide collaboration and BIM advancement (Bucher and Hall, 2020; Radl and Kaiser, 2019) Efficient BIM implementation necessitates unifying solutions for acquiring, managing and utilising information and processes from the diverse project and enterprise-level systems, as well as integrating them with building models (Aram and Eastman, 2013).

The similarity between the current situation in construction and earlier with the manufacturing industry motivates the application of well-established manufacturing principles to construction. Well-established production methods may, however, flatten the BIM implementation (Aram and Eastman, 2013; Dave and Sacks, 2020). Earlier studies suggest that BIM improvements are based on Product Lifecycle Management (PLM) (Aram and Eastman, 2013; Jupp and Nepal, 2014; Li et al., 2021; Pourzarei et al., 2020); the adoption of Industry Foundation Classes (IFC) as the data model standard for delivering integrated building information (Dimyadi et al., 2016; Fu et al., 2006); the implementation of situationbased management approaches such as Last Planner (Bertelsen, 2005; Maraqa et al., 2021; Sbiti et al., 2021; Schimanski et al., 2020); proposing a central information repository as a multi-disciplinary collaboration platform (Ding and Kohli, 2021; Hamidavi et al., 2020; Ng et al., 2020; Singh et al., 2011), and modularisation through conceptualising buildings as products (Bertelsen, 2005; Sharif et al., 2022). These methods have common goals with BIM, 
including process fluency, and product data integrity among multiple systems through standardised information repository across building (product) lifecycles. Opportunities for advancements in the way that product and product-related data is structured in the construction industry have the potential to provide standard contextual building blocks similar to those found in PLM domains (Boton et al., 2018).

\subsection{Productization}

Productization is often used interchangeably with standardisation, systematisation, productivisation, industrialisation and commercialisation. Productization is the standardisation of elements of an offering (Guvendiren et al., 2014) and concerns all activities before a product is ready commercially (Pyron et al., 1998). Productization is seen as a delivery-oriented concept (Kuula et al., 2018) that enables optimal balance between customisation and standardisation as well as the ability to make and sell (Zhang et al., 2017). It provides the necessary systematics to bring the offering under control so that company processes can perform (Harkonen, 2021).

Productization refers to the transformation of custom, or incidental products rather than standard ones (Leenen et al., 2012). Productization is a transformational process where product information and materials are streamlined (Suominen et al., 2009; Wirtz et al., 2021), systematised and standardised through replicable methods and transparent formats (Kankaanpaa and Isomaki, 2013). The integration of design information and material flows into the rhythm of production has proven critical to productization (Lehtovaara et al., 2021). Productization is seen as a process that bridges inputs and outputs. The Transformation-Flow-Value theory proposed by Koskela (2000), sees transformation from inputs to outputs as a flow towards fulfilling customer needs and adding value. Productization is also defined as a transformation process from customer-specific products (low-productized) to standard, mass-market products (high-productized) (Mörschel et al., 2007; Simula et al., 2008), where rationalisation is necessary to produce deliverables from individual-level, tacit, abstract knowledge to organisation-level, easier-to-communicate knowledge (Heusinkveld and Benders, 2005; Simula et al., 2008; Valtakoski and Järvi, 2016; Zhang et al., 2017). The increase in the level of productization increases the clarity over offerings, and they become more understandable and communicable to customers (Simula et al., 2008) and stakeholders. Productization refers to the systematisation that enables analysing the offering and enables dealing with the related data (Lahtinen et al., 2021).

In a product-centric view, productization covers both new product development and marketing (Figure 1). Product management literature (Harkonen et al., 2018; Simula et al., 2008; Tolonen et al., 2014) further split productization into technical and commercial perspectives, or capacity-to-produce (inbound) and capacity-to-sell (outbound) activities. Inbound activities harmonise and systemise the offering delivery process, while outbound productization aims at improving product value for customers and providing wider product families to satisfy needs (Simula et al., 2008). There are related needs for active product portfolio management, including both, technical and commercial perspectives to cover products, and product families, optimise value and strategic fit and balance the portfolio (Tolonen et al., 2015).

Productization is strongly connected to module-based product development. Modularisation refers to product and process structures where design elements are divided into modules with well-defined interfaces and formal architecture (Kuula et al., 2018). The key to achieving efficiency in the productization process involves consistent and standardised PS (Harkonen et al., 2017). Companies cannot make full use of their existing systems without consistent PS and supportive data models (Hannila et al., 2019).

\section{Productization and product structure}




\section{ECAM}

Figure 1.

Systemic view on productization

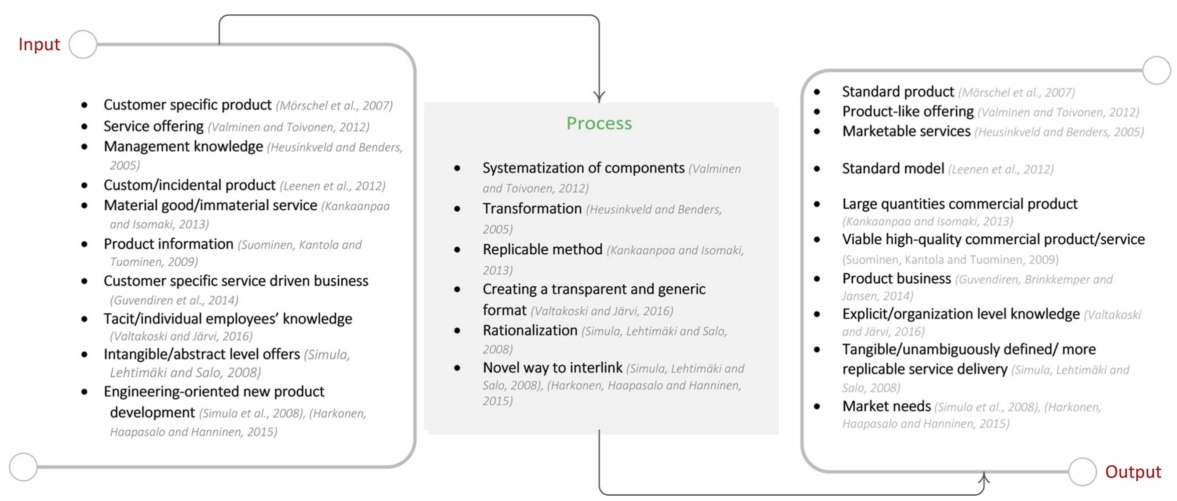

\subsection{Product structure (PS)}

PS is commonly used in various fields as product architecture (Belkadi et al., 2016), configuration model (Li et al., 2010; Mannisto et al., 1998), PS tree (Li et al., 2013) and modular PS (Windheim et al., 2017). A generic PS is an organised hierarchical and structural representation (Brière-Côté et al., 2010; Chu et al., 2009; Heimes et al., 2020; Pinquié et al., 2015) illustrating product's composition and assembly relationships (Belkadi et al., 2016; Binbin et al., 2011; Christ et al., 2013; Lu et al., 2011; Şenaltun and Cangelir, 2013). PS consists of either abstract or physical elements (Riesener et al., 2020; Sarinko et al., 2005), cover entire product families, show which modules and part types or classes are used in products or product families (Christ et al., 2013; Magnusson and Pasche, 2014; Mannisto et al., 1998; Venkatesh, 2015). PS forms a consistent unit that can be identified and its elements replaced (Belkadi et al., 2016), and supports managerial decision-making (Binbin et al., 2011; Zhang et al., 2017) and collaborative workflow by maintaining up-to-date design details (Şenaltun and Cangelir, 2013) so that they remain dynamic and reusable.

PS is a context-dependent basis for all product component information, including characteristics, technical objects and product-function requirements (Christ et al., 2013; Holle and Lindemann, 2014; Pinquié et al., 2015); where instantiated data is managed and stored (Harkonen et al., 2019b; Tichem and Storm, 1997; Wei et al., 2019) to realise product functions (Wu and Kimura, 2007). PS offers information on possible implementations of existing elements in a wide variety of similar products (Christ et al., 2013). To ensure that product data can be well handled and that change can be monitored and recorded, the product data should be managed according to the PS (Binbin et al., 2011).

Bill-of-Material (BOM) is the most common specific/precise PS, representing parent-child relations between product components. BOM consists of a list of all sub-assemblies, intermediates, parts and materials that form a parent assembly and show the quality of each assembly needed to produce complete products (Garwood, 1997; Liu and Wang, 2013). The terms PS and BOM can be used interchangeably in spoken language, however, "the definition of PS is more comprehensive" (Brière-Côté et al., 2010, p. 54) and BOM generally refers to single-level component lists required for manufacturing products (Boton et al., 2018; Saaksvuori and Immonen, 2008). At some point during product development, BOM is regarded as a basic, filtered PS snapshot (Pinquié et al., 2015).

BOMs tend to fall into two main types: Engineering Bill-of-Material (EBOM) and Manufacturing Bill-of-Material (MBOM). EBOM is the cornerstone of "as designed" PS, which describes "what" a product is (Elhariri Essamlali et al., 2016; Tekin, 2014) and is later converted into an MBOM. MBOM describes "how" the product is produced and assembled (Elhariri Essamlali et al., 2016) by maintaining manufacturing interactions through the 
planning of production processes (Tekin, 2014). The processes and implementation practices related to BOM significantly affect the integrated operation of systems like CAD, Product Data Management (PDM), PLM and ERP (Shih, 2014). PS has been described as the most important unit for data exchange among collaborative enterprises (Liang et al., 2010; Liu et al., 2021) and the basis for PDM implementation. PDM enriched by a unified PS serves as a central information repository for process and product history and facilitates integration and data sharing among all business users dealing with products (Shih, 2014).

\subsection{Literature synthesis}

The existing literature on productization, PS and the gaps in the effective BIM implementation demonstrates the embedding capabilities of product structures and productization, which show significant potential to address BIM gaps (Figure 2). Productization enables reliable transformation and handling of information through a structured data model. PS provides the structure as a consistent information unit, and base for design, building and sales processes, further enhancing the collaboration and integration of people and systems.

\subsection{PS in construction project context}

PS and productization principles seem very promising avenues with good potential to enable an information-centric management approach to design and construction, enabled by BIM. Given that the construction industry has similarities to other discrete manufacturing industries. This regardless of some notable differences. Despite the considerable potential of productization and PS concepts, only a few researchers have studied them in the construction context. A standardised product structure as an information repository has been argued to be the missing link between the BIM approach, disconnected construction processes and information systems (Boton et al., 2018; Harkonen et al., 2018; Holzer, 2014).

Kit-of-parts type product structure is proposed as a pre-designed and pre-engineered digital model to provide usability for building products, flexibility for design solutions and integration with metadata processes (Cao et al., 2021). Modelling technical and commercial offering also suit the construction project context (Harkonen et al., 2018). Something is needed as BIM implementation suffers from the lack of well-designed transactional structures,

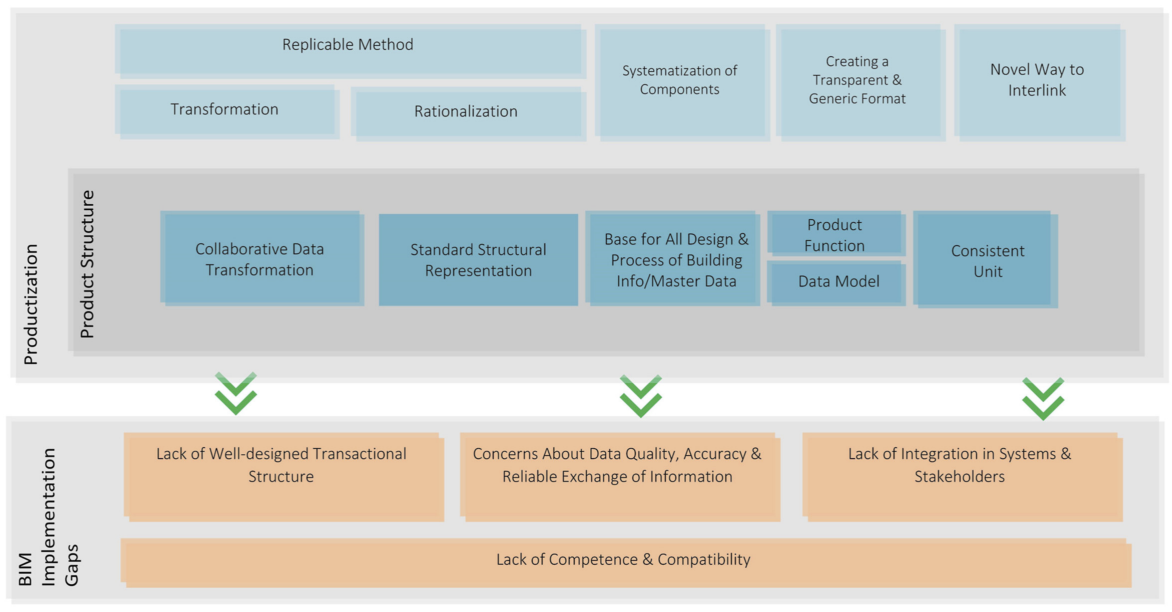

Productization and product structure 
concerns about reliable information flow and the lack of integration among stakeholders and systems. The shortcomings need to be addressed through a construction-specific PS. The dearth of studies in this field, and the potential of productization and PS in conjunction with BIM challenges (Figure 2) encourage to analyse the productization concept in a real case to see how productization and PS are defined and implemented in everyday work.

\section{Method}

The research method is qualitative. A qualitative study takes an interpretative, naturalistic approach to its subject with emphasis on the socially constructed nature of facts (Wilson, 2010). Qualitative research entails the investigation and collection of a wide range of empirical materials, including case studies, interviews, observational, historical and visual texts. This qualitative study is realised as a combination of conceptual research and a single case study.

The conceptual research yielded a literature synthesis on productization, PS and BIM implementation gaps which allows interpreting the potential of productization and PS in filling the BIM implementation gaps. Given the necessity for detailed, in-depth data collection involving multiple sources of information (Wilson, 2010), the study follows a single case study. The study applies the knowledge from the literature review and investigates the potential of productization and PS in a case company. This refers to methodological triangulation (Carter et al., 2014) where the results from the conceptual research approach and a case study are compared to assure the validity of the findings. Additionally, investigator triangulation (Denzin, 2017) was used, where multiple investigators debated the interpretation of findings during the data analysis, bringing together different perspectives using by Gioia methodology (Gioia et al., 2013). Building on the knowledge acquired from the literature review and the case study, we come up with a list of challenges in BIM and productization implementation. We used the list as criteria for developing a construction-specific product structure in a way that fulfil the requirements stated in both literature and case study. Then conclusions were drawn. Figure 3 depicts the key research activities and phases.

\subsection{Conceptual research}

This study aims to explore the core of productization and the application of PS to facilitate BIM implementation. To this end, the conceptual research began with a literature review on

Figure 3.

The research processes

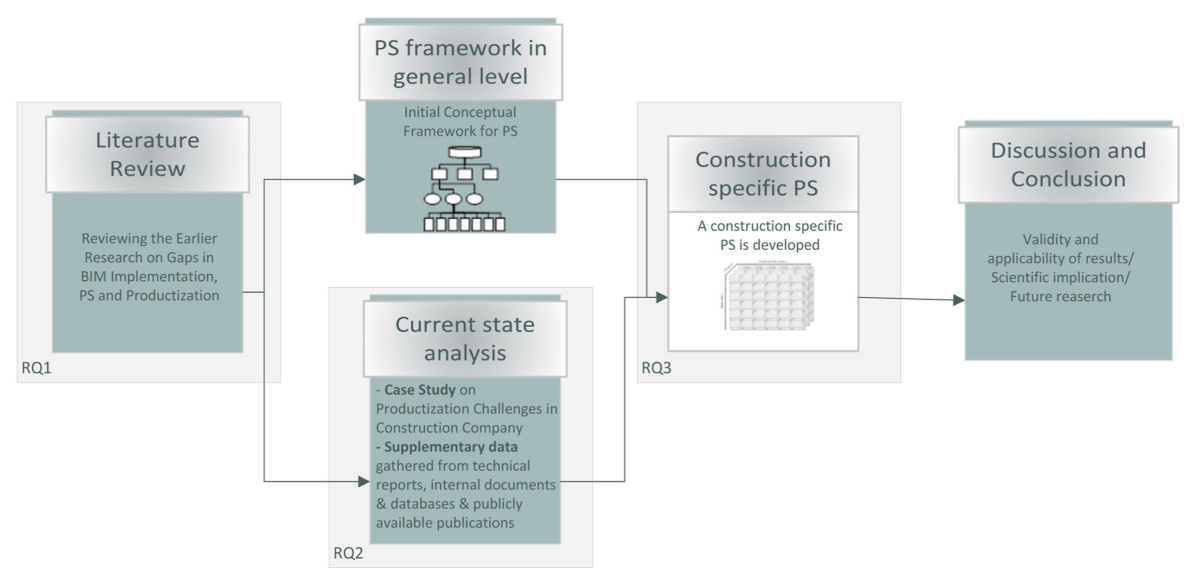


BIM implementation challenges. Then the potential of productization and PS were reviewed to see how those could fill the gaps in BIM implementation, as well as relevant linkages required for the research purpose.

A procedure for identifying, selecting, assessing and synthesising literature was followed in this study. As a result, first, a search was conducted to identify the relevant studies in line with the research objectives. In this case, Scopus has been used as the principal bibliographic database for article search because, with most scientific, technical and medical disciplines, Scopus is frequently suggested as a platform for collecting and assessing quality articles (Cavacini, 2015). Scopus includes highly selective and well-organised transdisciplinary abstracting and citation-tracking databases and offers more advanced methods for assessing academic publishing trends than other databases (Gasparyan et al., 2013). Despite the advantages of the Scopus, this study uses Google Scholar as a complementary database to reduce the publication bias (Thomé et al., 2016). For example, when evaluating collected articles, there were cases when references in a particular publication were in good alignment with the research objectives but did not appear due to Scopus' search string limitations. The authors utilised the Google Scholar database to maintain them in the research. The search keywords were determined through brainstorming among researchers and were based on the concepts under investigation; productization, PS and BIM implementation challenges.

Regarding productization, the keywords utilised are related to and include variations as well as semantically relevant terms of productization, so that the keywords should appear in the papers' title, abstract or keywords and be limited to the final public stage and English language. The following search strings are used to identify the relevant articles. There was no restriction to the date and exclusion criteria for research in this area and searches were conducted on 24th January 2020 and 208 papers are identified in this process. The process was repeated in December 2021 to ensure the inclusion of very recent articles.

"Title" OR "Abstract" OR Keyword ("Productization" OR "Productisation") AND (LIMIT-TO (PUBSTAGE, “final”)) AND (LIMIT-TO (LANGUAGE, "English”)),

In addition, we built our knowledge on the concept of Productisation on the foundation of a comprehensive systematic literature review (Harkonen et al., 2015) conducted previously.

Because the phrase PS is commonly used in articles whose primary focus is not on PS itself, but rather on disciplines and purposes beyond the scope of this research, the search was conducted in such a way that the term PS appears in the title, referring to the focus of study on this concept. Furthermore, irrelevant subject areas are excluded to avoid misunderstandings about PS. The following search strings are used to identify the relevant articles. There was no restriction to the date for the research in this area and searches were conducted on 20th February 2020 and 172 papers are identified in this process. The process was repeated in December 2021 to ensure the inclusion of very recent articles.

"Title" ("Product Structure") AND (LIMIT-TO (LANGUAGE, "English")) AND (EXCLUDE (SUBJAREA, "MATH") OR EXCLUDE (SUBJAREA, "CHEM") OR EXCLUDE (SUBJAREA, "BIOC") OR EXCLUDE (SUBJAREA, "PHYS") OR EXCLUDE (SUBJAREA, "PHAR") OR EXCLUDE (SUBJAREA, "MATE”) OR EXCLUDE (SUBJAREA, "CENG”) OR EXCLUDE (SUBJAREA, “AGRI”) OR EXCLUDE (SUBJAREA, "MEDI") OR EXCLUDE (SUBJAREA, "PSYC") OR EXCLUDE (SUBJAREA, “ARTS") OR EXCLUDE (SUBJAREA, "IMMU”) OR EXCLUDE (SUBJAREA, "NEUR”) OR EXCLUDE (SUBJAREA, "NURS"))

Concerning the BIM implementation challenges, the same steps followed, and the following search strings were used to ensure that the keywords appeared in the title, abstract, or keywords of the articles and that the search was limited to the final public stage and English language. There was no restriction to the date for the research in this area and searches were conducted on 20th February 2020 and 178 papers are identified in this process.
Productization and product structure 
"Title" OR "Abstract” OR Keyword ("Building Information Model* implementation" OR "Building Information Model* use" OR "Building Information Model* adoption" OR "BIM implementation" OR "BIM use" OR "BIM adoption" AND "challenges") AND (LIMIT-TO (PUBSTAGE, "final")) AND (LIMIT-TO (LANGUAGE, "English"))

After the first search phase, the abstract, main results and conclusion of all identified papers were initially reviewed to determine their relevance to the research questions. To this purpose, the following exclusion criteria were applied: papers that did not refer to the research topic or were duplicate items. The retrieved articles have been read in detail and used as the theoretical foundation of this research. A synthesis of the key concepts reviewed is drawn as illustrated in Section 2. The synthesis contributed towards forming the initial framework for a conceptual PS, the formulation of interview questions and supported during case study interviews.

Two researchers conducted an in-depth analysis of the publications and came to an agreement on which studies should be considered in drafting potential interview questions to be utilised in the next stage of the research. The study applies the knowledge from the literature review and investigates the potential of productization and PS in a case company. As a result, the content of articles in the Productization and PS areas was reviewed to determine how productization and PS potential may be used to improve BIM implementation. The literature synthesis presented in Figure 2 also sheds light on the development of interview questions 1 to 5 .

Table 1 summarises the studies, including the number of identified articles and relevant articles based on exclusion criteria, retrieved references and interview questions.

\subsection{Case study}

The case company was chosen based on a common interest in understanding the role of productization and product structure in successful BIM implementation. The possibility of gaining access also contributed. The case company is a large Finnish construction enterprise, operations consisting of construction, and residential and commercial property development. The company use standardised concepts and construction methods, including factory-made modules and elements to improve the construction process and to enhance quality. Most importantly, they apply the productization approach to their construction projects. Using both primary and secondary data acquired from the case company, the current status of productization and the application of product structures were thoroughly examined.

Primary data were gathered through semi-structured interviews to narrow down inquiries (Rocco, 2003). The interview questionnaire (Table A1) was formulated based on literature findings (Figure 2) (Mason, 2004). The semi-structured interview template was divided into three sections. The first section consists of introductory questions on product and product development definitions that aim to focus the interviewees on the under-discussed themes and pave way for the study's key objectives. The second section consists of three broad subsections that examine the productization concept from its definition, content, process, practices and outcomes from both technical and commercial standpoints. In addition, challenges of product development and productization in construction projects were discussed, with a particular focus on the importance of a consistent product and production information repository. The third part of the semi-structured interview was designed to investigate under-discussed topics as an open discussion to gather interviewees' thoughts and opinions on not-yet-discussed but critical issues in the construction industry regarding challenges of productization and the lack of centralised product/production information. The interviews concluded interviewees' suggestions for productization improvements. Interviewees were provided with the interview guide beforehand to allow preparing for discussion. The interviews were recorded and transcribed to allow detailed analyses. 


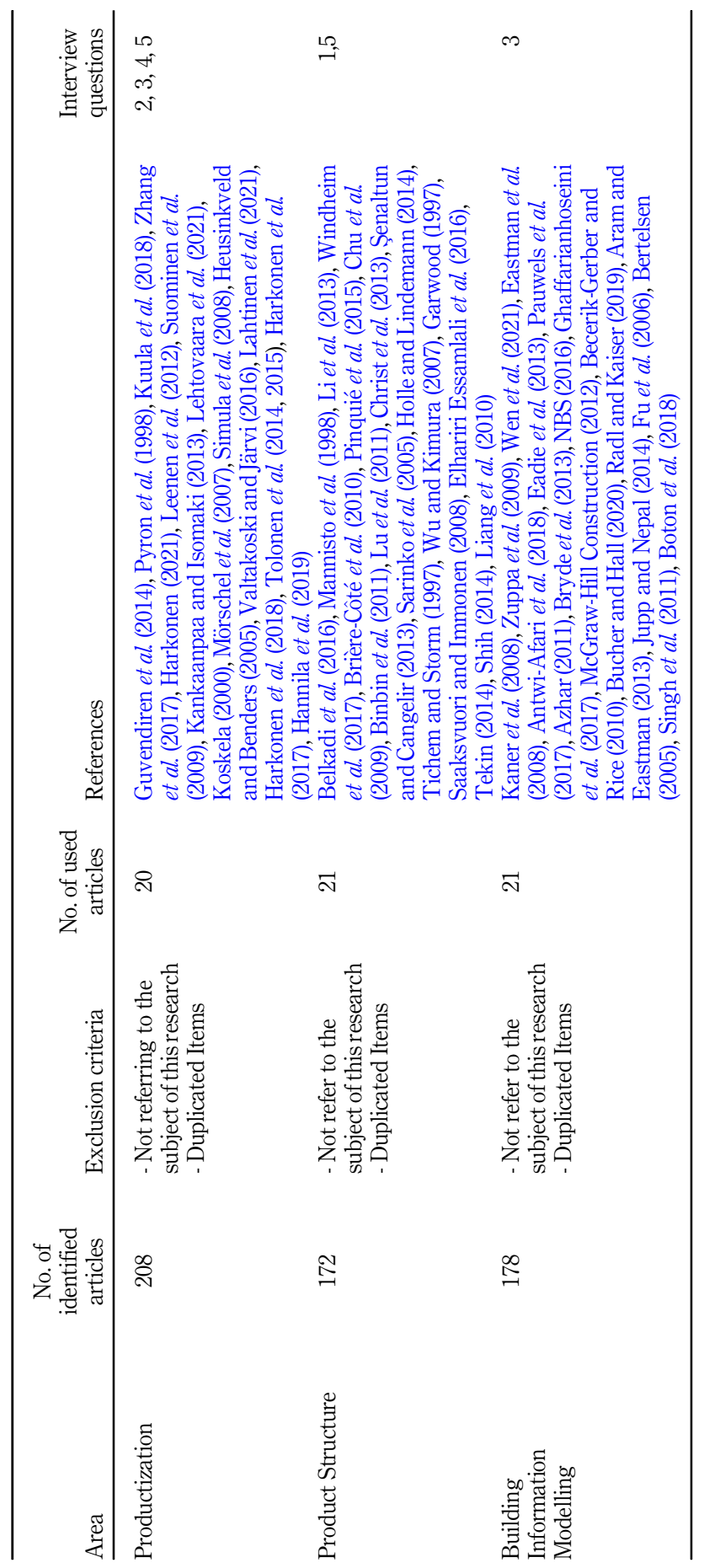

Productization and product structure

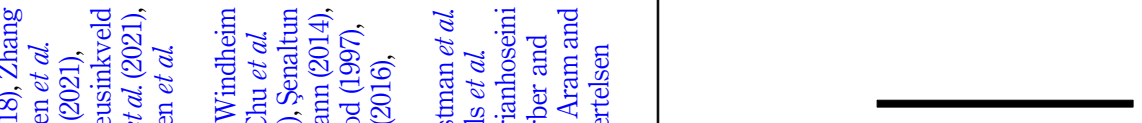

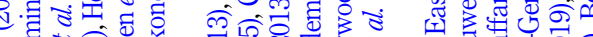

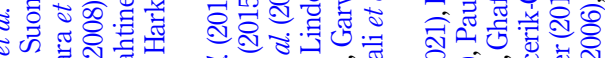

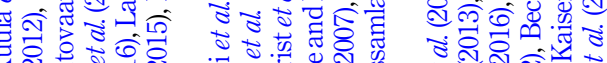
过

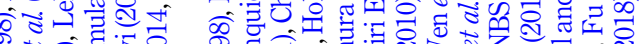

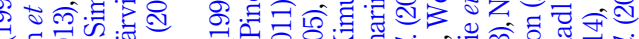
过灾活

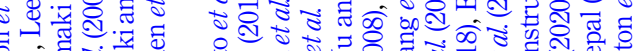

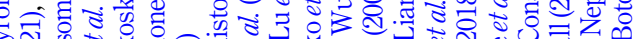

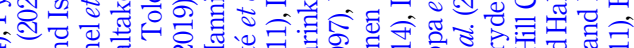
घี 융요

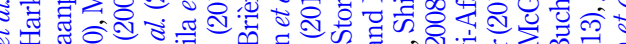

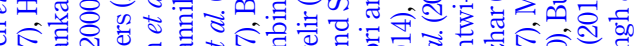

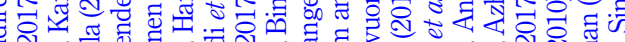

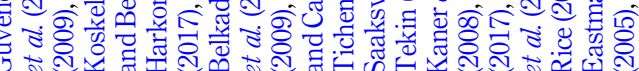

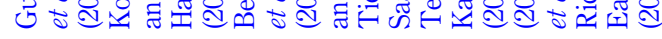

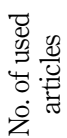

จ

Table 1. Included studies and linkages to research questions 
Conceptually driven purposive sampling (Farrugia, 2019) was used to select the interviewees. This purposive sampling approach aimed to find the most information-rich cases to provide a solid answer to the research question. To pick initial candidates for interviews, the researchers met with the case company's Chief Development Officer (CDO), who has led several productivity improvements projects in the case company. The research's emphasis has been discussed, and potential subprocesses and activities associated with productization and centralised product data have been identified. Then the CDO proposed a list of potential interviewees with detailed information regarding their qualifications, their experience and role in the case company. Researchers reviewed the list of candidates to ensure that we are interviewing a diverse range of people with varying backgrounds and experiences who are familiar with the topic of the research and may have differing ideas or experiences with it. This helped to ensure that our data are balanced and accurately reflect the opinions and experiences of the population being studied. The potential individuals were then asked if they wanted to participate in the interviews, resulting in a rather limited pool of candidates.

Snowball sampling (Farrugia, 2019) was therefore applied: suggestions for possible candidates were requested from the initially identified participant pool. Suitable sample size for a qualitative study is necessary to adequately answer the research questions (Marshall, 1996), hence four interviews were conducted with selected interviewees, including top-level managers with extensive experience in design, procurement, construction, prefabrication and BIM. The more specific list of interviewees' specialisations in terms of qualification, years of experience and current role in the case company is presented in Table 2.

The amount of gathered primary data from the interviews is seen adequate to answer the research question. Nevertheless, the supplementary information provided by the case company is used to support the primary data including internal materials - internal publications and documents - and public information. The secondary material is used indirectly in search of information related to the study objectives, which may be stated unintentionally in the available sources. The assessed documents included the product-related bill of materials through with the researcher had access to see how a product structure is designed in different products and let them evaluate details about both technical and commercial perspectives. A variety of product modules, from customer-specific to standard, are analysed to determine the function of the unified information unit in the productization process. In this section, the product structure and manufacturing processes of kitchen and bathroom modules, as well as

\begin{tabular}{|c|c|c|c|}
\hline Role & Qualification & $\begin{array}{l}\text { Years of } \\
\text { experience }\end{array}$ & $\begin{array}{l}\text { Years of experience } \\
\text { regarding the area of } \\
\text { study }\end{array}$ \\
\hline $\begin{array}{l}\mathrm{R} \& \mathrm{D} \text { and productization } \\
\text { project manager }\end{array}$ & $\begin{array}{l}\text { - R\&D } \\
\text { - Productization } \\
\text { - Product development } \\
\text { - BIM }\end{array}$ & 26 & 26 \\
\hline BIM manager & $\begin{array}{l}\text { - BIM } \\
\text { - Design and cost calculation }\end{array}$ & 12 & 7 \\
\hline Chief Procurement officer & $\begin{array}{l}\text { - Sourcing and procurement } \\
\text { - Productization } \\
\text { - Product development }\end{array}$ & 23 & 20 \\
\hline Factory manager & $\begin{array}{l}\text { - Premanufacturing at factory and } \\
\text { construction at the site } \\
\text { - Productization } \\
\text { - BIM }\end{array}$ & 15 & 15 \\
\hline
\end{tabular}

Table 2.

Interviewee details 
some completely finished apartments manufactured on the production plants, are reviewed for over ten products. Through related information systems such as PDM, ERP and CRM, the company allowed access to their product and production information. This provided a full perspective of a product's productization, including the development phase, technical components and commercial procedures. Furthermore, the case company's annual report for the past five years was studied to follow the case company's productization and industrial prefabrication strategies from a commercial standpoint. These reports are publicly available and contain comprehensive information regarding industrial manufacturing and the level of productisation of the case company's products based on information gathered from their factories. Overall, the product structures of 10 products are studied in detail, as well as five annual reports totalling more than 500 pages. In addition to extensive discussion interviews, the researchers have attempted to use the available data in connection with the study's objective. When additional data did not affect the coherence of the emerging concepts, clarity, or linkages, the data collection was deemed as saturated.

\subsection{Empirical data and analysis}

A systematic approach was applied for analysing the gathered data to enhance the qualitative rigour. The Gioia methodology is a systematic conceptual and analytical discipline aligned with the grounded theory that enhances the reliability of data interpretation and boosts plausibility and defensibility of conclusions for readers. Gioia methodology consisting of three sequential steps shows the data structure, explaining how the collected data were analysed in this study. The collected data were analysed by following three sequential steps to conduct a pattern from empirical data. Data analyses were carried out using NVivo software following the guidelines for node-based thematic analysis (Bergin, 2011) to ensure process rigour and to facilitate data management (Bazeley and Jackson, 2013). NVivo facilities reliable coding of quotations collected from the interviews and speed up the process of building themes across the qualitative data analyses.

A comprehensive summary of responses was produced from interview transcripts coded and classified into a manageable number of groups based on quotation similarities. The identified groups were given phrasal descriptions which develop "Discussed Concepts". Quotes in line with the research objectives were extracted, coded by phrasal descriptions and categorised based on similarities as "Categories". Coding focused on determining productization challenges from both a technical and a commercial perspective, as well as the role of centralised product/production information in supporting productization. Finally, based on the linkages found among the identified Categories in the previous stage, aggregate dimensions were developed to construct wider classes that bring relevant concepts together as "synthesised productization challenges". Multiple investigators discussed the interpretation of the findings iteratively over the consecutive phases of the Gioia methodology. Eventually, they all formed a data structure (Figure 4). The empirical data from both the introductory and focused questions are presented in the five sections that follow. Within the productization challenge section, the data structure of the important findings of the study's key objectives is presented and analysed in detail.

3.3.1 Product definition. Product and related terms were defined based on the interviews, at both industry and company levels. The product was defined mainly as a building, such as a house, for simplicity reasons. Some gave broader definitions and mentioned the end-product and the end-result of company activities. Each individual component, building block and building element can also be seen as a product (sales item). Customer-oriented products were defined as anything manufactured for customers. The products in construction projects were primarily seen as something non-service related.
Productization and product structure

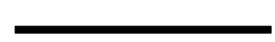




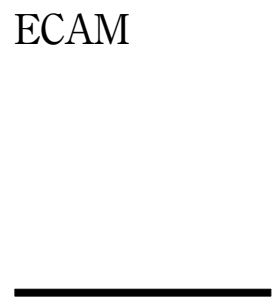

Figure 4.

Synthesised productization challenges in construction (Data Structure)

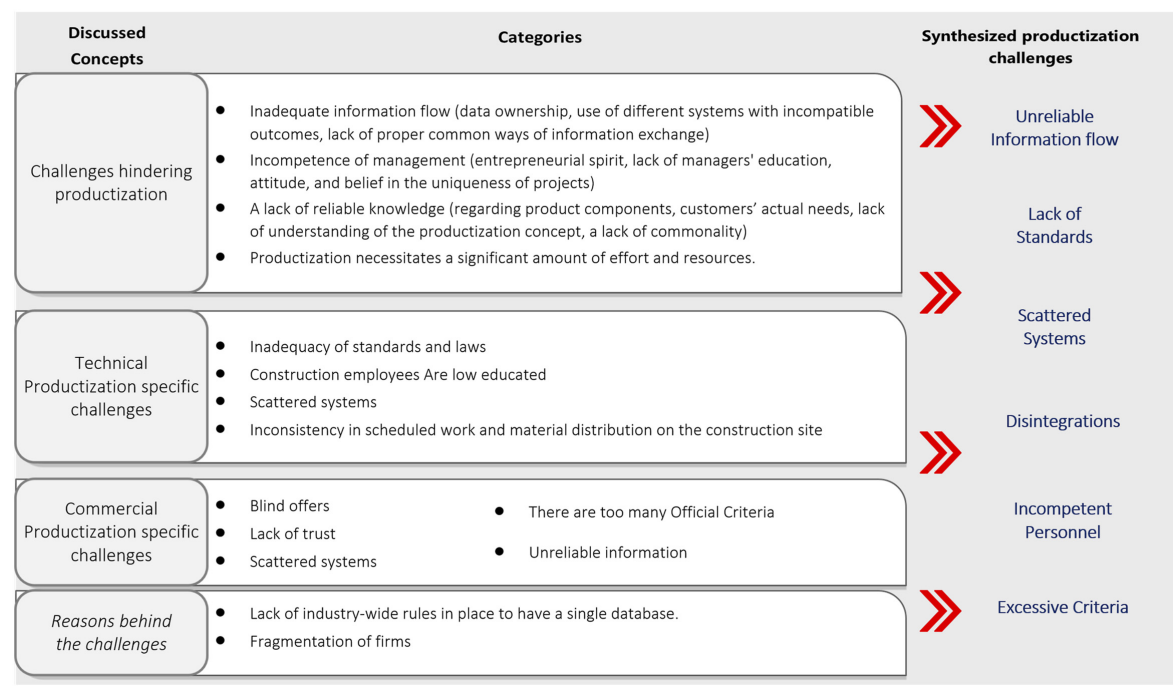

3.3.2 Product development definition. Product development is seen as the starting point of production that aims to add value to end-products based on identified needs. Product development is distinct from product design and is a broader concept. Product design is known as a product-specific concept in construction that is implemented once for a particular end-product and is not repeatedly useable for other products. Product development also occurs once but can be used repeatedly in many end-products. Interviewees emphasised how manufacturability, cost and a product's commercial aspects need to be continuously considered during the product development process.

3.3.3 Productization definition. Productization was characterised as an ongoing process in the construction business. Productization deals with end-products' technical, commercial and cost aspects, starting with the concept to be produced, and continuing with designing the required parts to create a volumetric product before it is commercially available. The interviewees' answers to the introductory questions demonstrated their basic understanding of products, product development and productization, and paved the way for discussing the study's key objectives.

3.3.4 Productization challenges. Productization challenges in construction projects were categorised into four main groups during the discussion: general level, lack of information flow and reliable knowledge, managers' incompetence, and the amount of required work and resources.

The main productization challenges identified from a technical standpoint include lack of standards, scattered systems, inconstant workflow and required materials. The main commercial productization challenge was seen to involve inaccurate information provided by distributed systems in construction projects. Such information is difficult to trust.

In addition to the identified challenges, it was mentioned that too many official criteria result in blind offers to customers. The root causes for productization challenges were seen to involve lack of rules for common databases, believing in one-off construction, and fragmentation of firms within the industry.

3.3.5 Centralised product/production information. The interviewees acknowledged the centralised product/production information unit as a key concept for productization. An information unit including product and production information promotes productivity in 
construction sites. It enhances decision-making, enabling people to learn from previous experiences.

The main challenges of productization in construction projects recognised from empirical data include unreliable information flow, lack of standards, scattered systems, disintegrations, incompetent personnel and excessive criteria (Figure 4).

3.3.6 Summary of challenges hindering BIM and productization. Table 3 shows the challenges hindering successful BIM implementation as discussed in the literature (first column) and emerged productization challenges from empirical evidence (second column). The results gathered from both the literature and the empirical study show similar concerns. The challenges outlined in Table 3 could be used as criteria for evaluating the concept and developing PS capabilities to facilitate BIM implementation.

The only challenge hindering BIM implementation that was not detected in the interviews involves integration among stakeholders. Since the study's objective is to propose PS to improve both the use of BIM and productization in construction, stakeholder involvement was also deemed in the scope. Lack of managerial competence is outside the scope and is not addressed further. The identified common challenges clarify the expectations for the solution to fill the gap. The following requirements (the list as criteria) represent the most important criteria expected from the framework:

The PS shall have a standardized transaction structure that allows for logical and consistent data flow.

The PS Facilitates the integration of people and systems.

\subsection{Findings}

3.4.1 Conceptual framework for PS. This research draws from both the literature and empirical evidence to develop conceptual PS at both, general and construction-specific levels. General PS is first presented based on the content, structure and capabilities discussed in the literature. The general PS is further cross-checked against the literature findings and empirical evidence to ensure the most suitable solution to the presented challenges. The following sub-sections discuss the PS concept and the development of the constructionspecific model.

3.4.2 General-level PS. The content and essence of product structures have been discussed in the literature in terms of hierarchical elements containing information from technical and commercial perspectives. Figure 5 shows PS, including the hierarchical elements of the product (left) and their respective units of information (right). This two-dimensional view of PS provides insights into the PS through the information-flow lens.

The utilised product part of the hierarchy structure starts with the product family, including different products, and displays alternative modules and components that could be used in products or the product family. Depending on the detail level, the product element could refer to various product configurations or versions. Information units correspond to the

\begin{tabular}{|c|c|}
\hline Gaps in BIM implementation (see Figure 2) & $\begin{array}{l}\text { Productization challenges (see } \\
\text { Figure 4) }\end{array}$ \\
\hline $\begin{array}{l}\text { - Lack of well-designed transactional structure } \\
\text { - Concerns about data quality, accuracy and reliable exchange of } \\
\text { info } \\
\text { - Lack of integration of systems and stakeholders } \\
\text { - Lack of competence and compatibility }\end{array}$ & $\begin{array}{l}\text { - Lack of standards } \\
\text { - Excessive criteria } \\
\text { - Unreliable information flow } \\
\text { - Disintegration } \\
\text { - Scattered systems } \\
\text { - Incompetent personnel }\end{array}$ \\
\hline
\end{tabular}

Productization and product structure 


\section{ECAM}

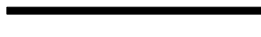

Figure 5.

PS of (a) hierarchical product elements and (b) their respective information units

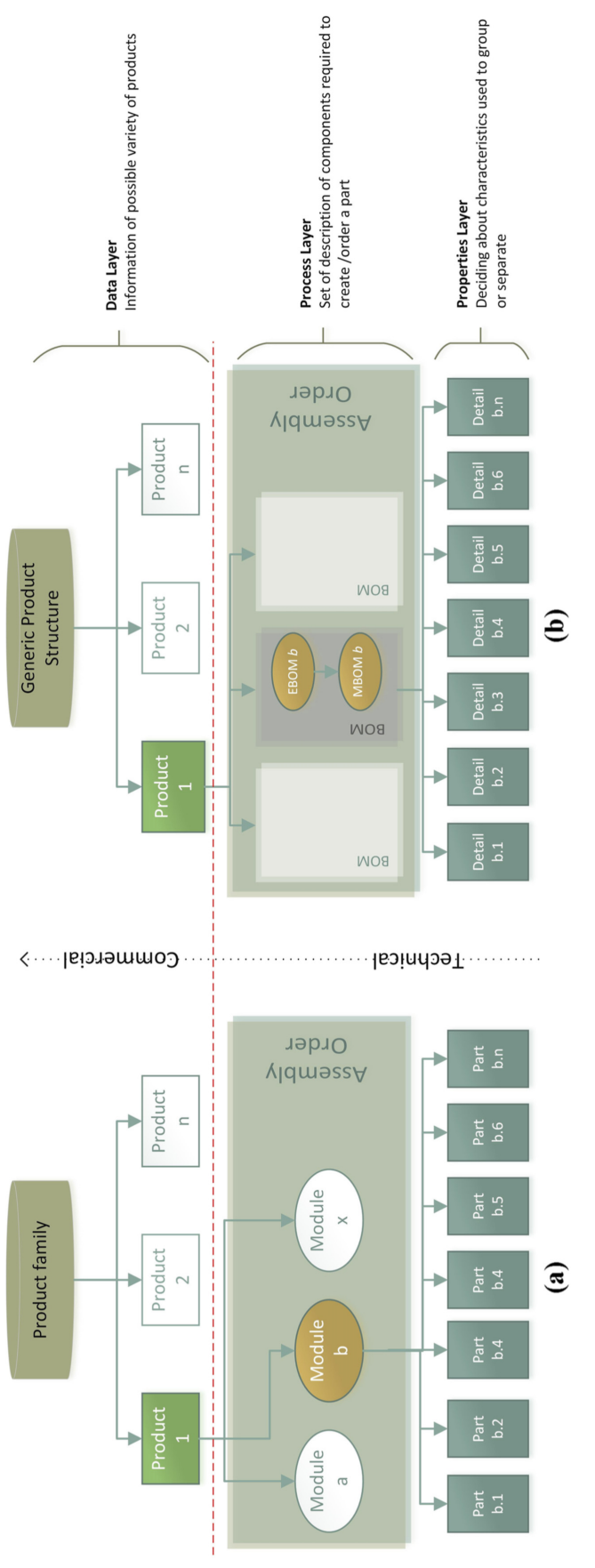


PS elements illustrated on the right side of Figure 5. Information on possible product variety (product data layer) is stored as a generic PS. The next level is the assembly process layer that includes the component descriptions required to build or order a part. At this level, BOM, including EBOM and MBOM, describe "what" the product is and "how" the product is produced and assembled. Detailed information on the parts that specify the characteristics used for grouping or separating them is stored within the properties layer.

The findings indicate that PS consists of comprehensive information regarding a product and production process with a clear structure of relations between units of detailed information. A centralised and standardised PS makes consistent information units accessible and easy to follow for all the stakeholders involved over the construction project lifecycle. PS enables timely and reliable information exchange between technical and commercial parties in an integrated and well-designed manner. These aspects show potential to address the lack of standardised transaction structure and issues about reliable information exchange, which have been identified as BIM and productization challenges. Furthermore, system and stakeholder disintegration could be tackled with standardised PSs that are simple to access and follow for all the stakeholders. This should improve the productization of construction products. Meanwhile, the information in a PS can be tracked and reused to enhance the flow of information between the technical and commercial sides of the business and increase the level of productization.

3.4.3 Construction-specific PS. The case study results and the literature review support the creation of construction-specific product structures. The capabilities of PS and the challenges hindering BIM and productization build expectations for assessing the applicability of a construction-specific PS. The proposed PS is expected to fill gaps in BIM and productization by allowing for a consistent information exchange structure that will enhance stakeholder collaboration and integration through a standard approach.

Consistent information exchange as an inherent feature of PS is discussed in this study at a general level. Detailed, well-organised product information on parts and assembly orders offers a consistent technical source of information and strengthens the ability to benefit from productization. A harmonised development process, with minimal confusion and duplication of tasks by existing systems and modules, is enabled by consistent technical information. The flow of reliable information from technical to commercial sides of business enhances the ability to sell the commercial aspects of construction products. This is an iterative and dynamic information flow process from technical to commercial sides, and vice versa. With regards to BIM implementation, the need for a well-designed transactional structure for information integration and exchange among involved parties could be well addressed by PS.

To standardise, a general-level PS could be enriched by a construction object library. Standard, hierarchically organised databases called "Construction Classification Systems" that are used to provide standardised technical building objects. The objectives of the UniFormat classification systems are in line with the objectives of this study, as they "enhance reporting of design program information, especially for preliminary project descriptions and performance specifications, and provide a basis for systematic filing information for facility management, drawing on details, BIM objects, and construction market data" (UniFormat, 2010, p. 1). In this classification system, building elements are hierarchically grouped into three levels (Charette and Marshall, 1999) that need to be acknowledged simultaneously to ensure that coherent, reliable and structured knowledge is shared by various stakeholders in the construction project lifecycle.

Inspired by the Part-Template-Matrix (Christ et al., 2013), the integration of PS into a classified object library improves the consistency of information exchange and knowledge re-use. The Part-Element Matrix (Figure 6) is distilled from the Part-Template-Matrix (Christ et al., 2013, p. 5) and shows PS dimensions and their interactions with the classified object library. The approach provides the basis for systematic information flow across projects and
Productization and product structure 


\section{ECAM}

Figure 6.

Developed Part-

Elements Matrix

illustrating

substructure and shell

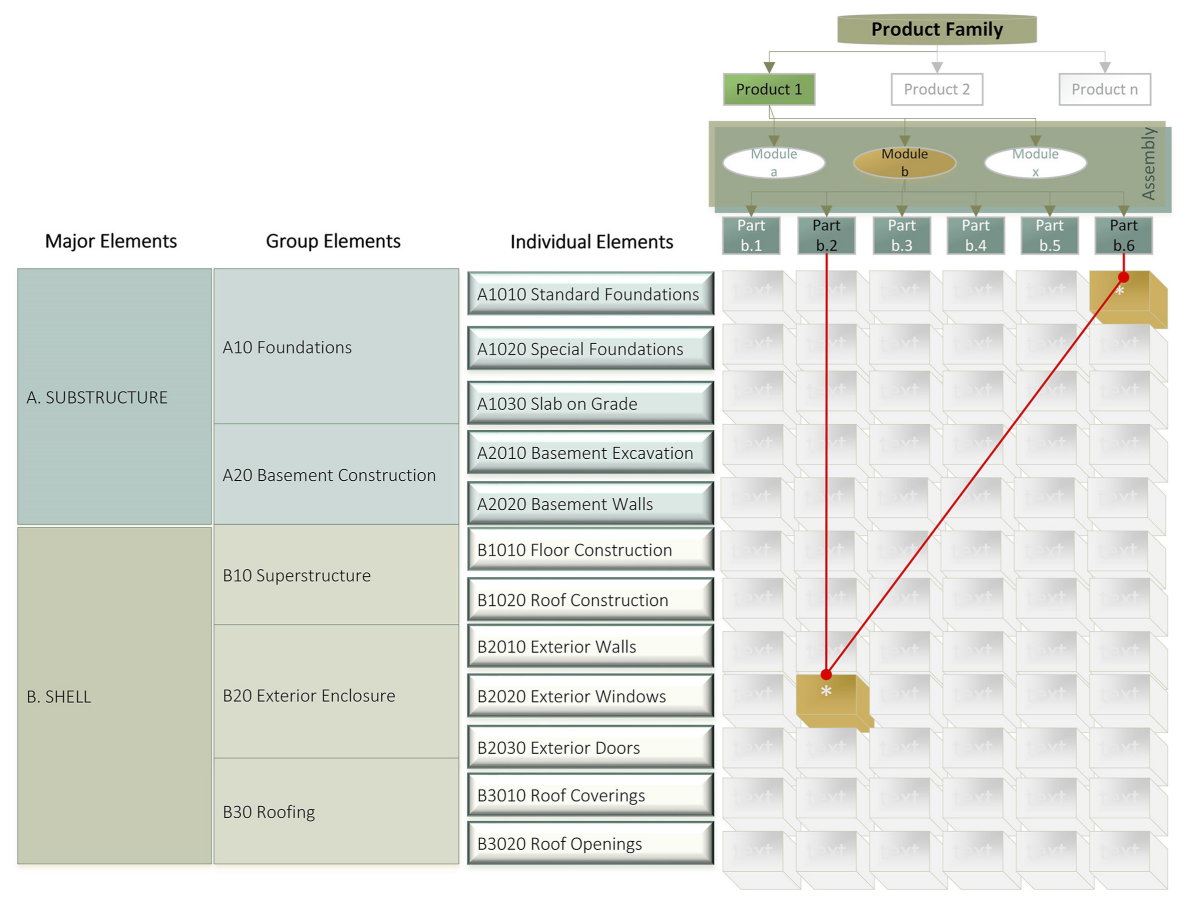

adds a standard classification of elements. As a result, a consistent and standardised database supports the PS, and simultaneously processes are integrated with information flow traceability. The targeted standard library of construction objects consists of three layers, including major group elements, group elements and individual elements. These levels correspond to the PS hierarchy of products, modules and parts. The major elements of Substructure and Shell were used based on the UniFormat classification system as examples while illustrating the developed matrix. The red line shows which library elements are used in specific parts. Hierarchically structured, the standard library of building objects further facilitates efficient information exchange among stakeholders. A well-organised PS has the potential to be used as a shared coordination unit among internal and external parties.

As illustrated in Figure 6, the line from element no. B2020 (exterior windows) goes to part (b2) of the PS, meaning that element no. B2020 is used in part b2 to form module (b) of product 1 .

The Part-Elements Matrix can improve the reliable exchange of information and integration to some extent, but the collaborative stakeholder engagement is also an issue in successful BIM implementation and productization. Hence a third dimension regarding stakeholder/user engagement might be necessary to involve different disciplines within the construction phases (Figure 7).

The addition of a user dimension could improve the collaborative use of the proposed PartElements Matrix. A new dimension referred to as the phases layer is included in the proposed matrix. As a result, a three-dimensional Part-Phase-Elements Matrix has been formed to demonstrate the relationships between parts, elements and users. Part-Elements Matrix capacities form the basis and allow stakeholder engagement (phases) to enhance BIM. The traceability of processes is improved and the need for responsible operators to ensure data accuracy is addressed. Figure 7 illustrates the same example, adding a phases layer that 


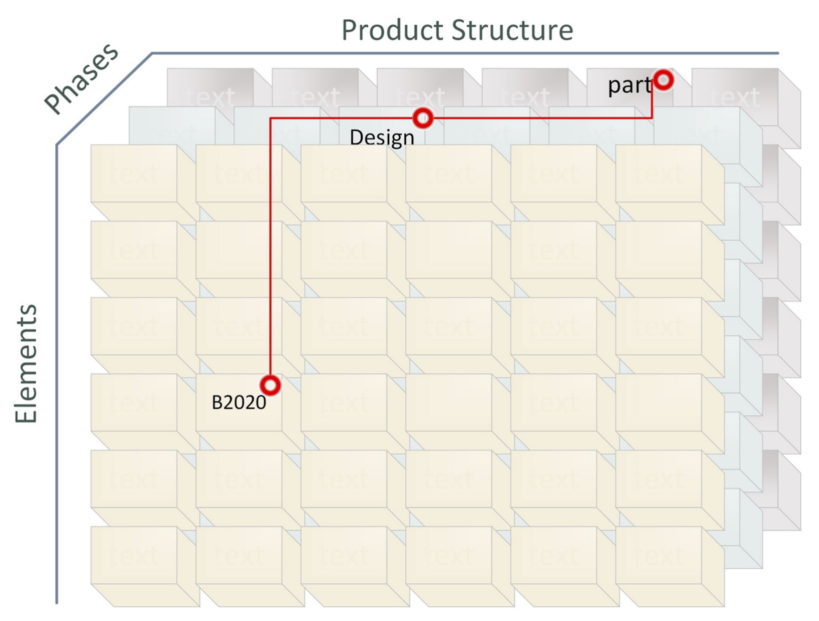

Productization and product structure

Figure 7.

The Part-Phase-

Elements matrix

shows stakeholder engagement in the connection between elements and the PS. In this example, element no. B2020 is used in part b2 by User (x) in the Design phase.

\section{Discussion}

BIM as a common environment for construction-related information throughout the lifecycle of a construction project shows a great promise to improve productivity. Nevertheless, specifically the challenges in terms of the collaborative side of activities and allowing consistent handling of data to improve system integrations should be addressed. The right type of data at the right time for use are required for all the stakeholders throughout the construction project. A consistent data interchange mechanism would be required. This study provides new insights into how to facilitate BIM implementation. BIM and the evident gaps in BIM implementation are approached through the perspectives of product structure and productization to enable an information-centric management approach to design and construction.

The PS and productization concepts seem to have inherent potential to address BIM implementation challenges from the information management perspective. Specifically, information consistency would be possible via the consistent handling of data. Trustworthy information is necessary from all construction phases in a systematic and consistent manner. The consistency is enabled by the structural consistency when the construction offerings are productized according to the same logic and the structure is considered. This will further allow transactions, enable trust in data and support system integrations, which are not supported by the current BIM. This realisation has strengthened our hypothesis in that PS seems a promising starting point for addressing BIM challenges in the scope of this paper. The indication that PS acts as a standardised data model with a logical structure and is possible to be understood equally by all seem to truly facilitate collaborative information transactions. These findings support Boton et al. (2018) in that a central structuring backbone is required for the BIM approach. Several concepts for structuring information are used in building projects, but the linkage between them remains unclear. This can be seen in the challenges that BIM implementation is facing. In this respect, this study is novel by offering a systematic view (Input, Process, Output) over the productization definition. Productization systematises product description and streamlines product information and materials via the product structure. This realisation may benefit BIM implementation and the construction industry. 
The findings highlight how productization has the potential to contribute to the systematization of the construction offering and the improvement of the efficacy of construction activities via the PS. This may enable the integrating and sharing of trustworthy information from all construction phases in a systematic and consistent manner. The current BIM has been lacking in enabling consistency and truly collaborative use. The results provide new empirical evidence to support Holzer (2014) in that PS is a central piece of every integration system and is seen as the missing link in the BIM approach. It is in line with Pauwels et al. (2017) in making it possible to link diverse information based on different formats by forming a basic data structure. Similarities between the challenges hindering BIM implementation and productization have further strengthened our confidence in PS as an effective method of facilitating consistency in information and addressing the current BIM gaps. The findings represent outstanding criteria expected from the PS framework. This appears to pave the way for a gap-filling solution based on the requirements outlined in the literature and the findings of the case study. The results point to the need for a standard transaction structure that allows people and systems to collaborate in a rational and consistent manner.

The development of PS seems to support productization and BIM implementation. We created a PS at a general level first, to represent PS from the perspectives of hierarchical product elements and the respective information units. The general level PS represents the productization approach in the created framework from both the technical and commercial aspects. We believe that such different lenses allow us to selectively focus on any aspect of the PS. As far as we are aware this is the first time that the PS has been considered in detail using the abovementioned lenses. The PS was further enhanced with aspects to make it more functional in the construction context. A general level PS with UniFormat construction object library was merged to respond to the need for standardized information transactions. This resulted in a two-dimensional matrix, named as Part-Element Matrix. The Part stands for the PS side, and the Element stands for the construction object library. UniFormat was chosen as it serves as a common classification system for representing construction objects and allows for the standardisation of consistent data flow. UniFormat also presents construction objects in three levels of building elements that are well-matched to the three-layered PS on the matrix's other dimension. Adding to Costa and Madrazo (2015), The Part-Element Matrix allows for more consistent parametric descriptions of products, easing their integration and processing by BIM. The Part-Element Matrix seems to address concerns regarding lack of defined standards (Aram and Eastman, 2013), insufficient BIM-compatible content for integration with other enterprise systems (Bernstein, 2012) and data incompleteness (Ghaffarianhoseini et al., 2017). The findings also facilitate more predictable and systemic implementation of takt production in construction (Lehtovaara et al., 2021) by increasing transparency, stability and reliability of information and process flow.

Further to address the collaborative perspective, to allow people and systems to collaborate in a rational and consistent manner, we propose a third dimension. The threedimensional matrix, Part-Phase-Element Matrix, consisting of general level PS, users from distinct phases, denoted by phase, and standard building elements dimensions. By employing a well-structured standard library element and adding a phases layer to the framework, this study adds dual value to the original Part-Template-Matrix (Christ et al., 2013) by making it standardised, equally useable by all, and allowing observation and tracking of changes. This is a significant contribution. The results share a number of similarities with Binbin et al. (2011) by indicating that PS aids in handling product data and monitoring and recording changes. The PS approach also supports Hall et al. (2020) in platformisation of digital manufacturing in construction, allowing the transfer and reuse of technological and process information while promoting an integral and collaborative approach to handling projects. The phase dimension of the Part-Phase-Element Matrix could 
also add new insights into the interoperable common data environment proposed by Bucher and Hall (2020). However, the flexibility of building and product lifecycle data descriptions have not been investigated in this study and further studies are needed in this regard.

\section{Conclusion}

A unified structured unit of information is essential in BIM implementation. The value of the proposed Part-Phase-Elements framework is derived from its conceptual and scalable structure for defining, managing and integrating project information, which should be transparent to everyone to address information flow issues of the BIM approach. The proposed framework is unique in multiple ways. Existing BIM implementation standards and protocols have a limited conceptual framework, which makes their application challenging. The ease of use of our framework is critical for its implementation in complicated projects by users of various backgrounds and skill levels. The proposed framework gives a scheme of building blocks for a consistent information flow in construction projects and simplifies the extant complex mechanism to cause fewer errors. The framework's uniqueness stems from using already known concepts to produce a unified entity. The framework highlights the importance of synergy, emphasising how to adopt a system-based perspective with the right concepts-PS - a standard building object library - and the users - in a combination can promote flow. The framework is developed upon empirical requirements articulated in the literature and the investigated case. Each of the framework's aspects, however, could be expanded to the utmost level of sophistication to facilitate the flow of information while remaining easy to users. An additional but not unexpected finding, not considered in the original aim, was that Productization and BIM implementation in building projects reveal essentially identical challenges, which could be due to their common mission in enabling integrity among multiple systems. This highlights the importance of a unified information unit in the successful implementation of integration-oriented approaches. More definite conclusions will be possible via further in-depth studies.

Our framework aims to pave way for developing unique means to combine crossindustry concepts in a systematic way, advancing the literature on productization and BIM implementation in the construction context. We expand concurrent construction and prefabrication literature from an information management perspective by incorporating ramifications of productization into the BIM implementation approach. The findings provide practitioners and researchers with a conceptual foundation for defining, managing and integrating building project information in real-world construction projects, allowing to investigate the validity further. While the limitations of conceptual findings and the case study approach are recognised, this study reveals new cross-industry insights to aid collaborative information flow in building projects. Examining more cases might be able to further reveal the true applicability of the framework. However, the analysed company has taken steps to achieve an industrialised operational model and have e.g. structural design office and element factory within the same group. The proposed framework has only undergone weak validation through discussions with relevant practitioners. In addition to testing and validating the framework, future studies could include topics such as imposing restrictions on user access levels and exploring the balance between individual requirements of various stakeholders (differentiation). Also, ensuring the standardisation and commonality of product components might prove an interesting topic to study further. Consistent with Dubois and Gadde (2002), it is possible to further expand on the standardisation aspect of the proposed PS to promote standardised activities, as has tended to be the norm in other industries. A longitudinal follow-up study will be conducted when the case company begins implementation of the industrialised operational model.
Productization and product structure 


\section{References}

Antwi-Afari, M., Li, H., Pärn, E. and Edwards, D. (2018), "Critical success factors for implementing building information modelling (BIM): a longitudinal review", Automation in Construction, Vol. 91, pp. 100-110.

Aram, S. and Eastman, C. (2013), "Integration of PLM solutions and BIM systems for the AEC industry", 30th International Symposium on Automation and Robotics in Construction and Mining, Montreal, Canada, doi: 10.22260/ISARC2013/0115.

Azhar, S. (2011), "Building information modeling (BIM): trends, benefits, risks, and challenges for the AEC industry”, Leadership and Management in Engineering, Vol. 11 No. 3, pp. 241-252.

Babič, N.Č., Podbreznik, P. and Rebolj, D. (2010), "Integrating resource production and construction using BIM", Automation in Construction, Vol. 19 No. 5, pp. 539-543.

Bajjou, M.S. and Chafi, A. (2020), "Lean construction and simulation for performance improvement: a case study of reinforcement process", International Journal of Productivity and Performance Management, Vol. 70 No. 2, pp. 459-487.

Bazeley, P. and Jackson, K. (2013), Qualitative Data Analysis with NVivo, 2nd ed., Sage, Los Angeles, London, New Delhi.

Becerik-Gerber, B. and Rice, S. (2010), "The perceived value of building information modeling in the US building industry", Journal of Information Technology in Construction (ITcon), Vol. 15 No. 15 , pp. 185-201.

Belkadi, F., Buergin, J., Gupta, R.K., Zhang, Y., Bernard, A., Lanza, G., Colledani, M. and Urgo, M. (2016), "Co-definition of product structure and production network for frugal innovation perspectives: towards a modular-based approach", Procedia CIRP, Elsevier, Vol. 50, pp. 589-594.

Bergin, M. (2011), "NVivo 8 and consistency in data analysis: reflecting on the use of a qualitative data analysis program", Nurse Researcher, Vol. 18 No. 3, pp. 6-12.

Bernstein, H.W. (2012), "The business value of BIM in North America: multi-year trend analysis and user ratings (2007-2012)", Smart Market Report, McGraw Hill Construction, Bedford, MA, pp. 1-70.

Bertelsen, S. (2005), "Modularisation: a third approach to making construction lean?", Presented at the 13th International Group for Lean Construction Conference, Sydney, pp. 81-88.

Binbin, W., Gang, Z. and Yong, Y. (2011), "Research on constructing product structure of large airliners based on configuration item", International Conference on System Science, Engineering Design and Manufacturing Informatization, Guiyang, China, pp. 364-367.

Boton, C., Rivest, L., Forgues, D. and Jupp, J. (2016), "Comparing PLM and BIM from the product structure standpoint”, in Harik, R., Rivest, L., Bernard, A., Eynard, B. and Bouras, A. (Eds), Product Lifecycle Management for Digital Transformation of Industries, Vol. 492, Springer International Publishing, Cham, pp. 443-453.

Boton, C., Rivest, L., Forgues, D. and Jupp, J.R. (2018), "Comparison of shipbuilding and construction industries from the product structure standpoint", International Journal of Product Lifecycle Management, Vol. 11 No. 3, p. 191.

Brière-Côté, A., Rivest, L. and Desrochers, A. (2010), “Adaptive generic product structure modelling for design reuse in engineer-to-order products", Computers in Industry, Vol. 61 No. 1, pp. 53-65.

Bryde, D., Broquetas, M. and Volm, J.M. (2013), "The project benefits of building information modelling (BIM)", International Journal of Project Management, Vol. 31 No. 7, pp. 971-980.

Bucher, D. and Hall, D. (2020), "Common data environment within the AEC ecosystem: moving collaborative platforms beyond the open versus closed dichotomy", Proceedings of the 27th International Workshop on Intelligent Computing in Engineering (EG-ICE 2020) (virtual), Online, 1-4 July 2020, pp. 491-500.

Cao, D., Wang, G., Li, H., Skitmore, M., Huang, T. and Zhang, W. (2015), "Practices and effectiveness of building information modelling in construction projects in China", Automation in Construction, Vol. 49, pp. 113-122. 
Cao, J., Bucher, D.F., Hall, D.M. and Lessing, J. (2021), "Cross-phase product configurator for modular buildings using kit-of-parts", Automation in Construction, Vol. 123, p. 103437.

Carter, N., Bryant-Lukosius, D., DiCenso, A., Blythe, J. and Neville, A.J. (2014), "The use of triangulation in qualitative research", Oncology Nursing Forum, Vol. 41 No. 5, pp. 545-547.

Cavacini, A. (2015), "What is the best database for computer science journal articles?", Scientometrics, Vol. 102 No. 3, pp. 2059-2071.

Charette, R.P. and Marshall, H.E. (1999), UNIFORMAT II Elemental Classification for Building Specifications, Cost Estimating and Cost Analysis, National Institute of Standards and Technology, Gaithersburg, MD.

Christ, A., Wenzel, V., Faath, A. and Anderl, R. (2013), "Integration of feature templates in product structures improves knowledge reuse", Proceedings of the World Congress on Engineering and Computer Science, Vol. 2, WCECS, San Francisco, p. 9.

Chu, C.-H., Luh, Y.-P., Li, T.-C. and Chen, H. (2009), "Economical green product design based on simplified computer-aided product structure variation", Computers in Industry, Vol. 60 No. 7 , pp. 485-500.

Costa, G. and Madrazo, L. (2015), "Connecting building component catalogues with BIM models using semantic technologies: an application for precast concrete components", Automation in Construction, Vol. 57, pp. 239-248.

Dave, B. and Sacks, R. (2020), "Production control systems for construction at the nexus of Lean and BIM", Lean Construction, Routledge.

Denzin, N.K. (2017), Sociological Methods: A Sourcebook, Routledge, New York, NY.

Dimyadi, J., Solihin, W. and Marchant, D. (2016), "The design brief: requirements and compliance", Journal of Information Technology in Construction, Vol. 21, pp. 337-353.

Ding, C. and Kohli, R. (2021), "Analysis of a building collaborative platform for Industry 4.0 based on Building Information Modelling technology", IET Collaborative Intelligent Manufacturing, Vol. 3 No. 3, pp. 233-242.

Dubois, A. and Gadde, L.-E. (2002), "The construction industry as a loosely coupled system: implications for productivity and innovation", Construction Management and Economics, Vol. 20 No. 7, pp. 621-631.

Durdyev, S., Mbachu, J., Thurnell, D., Zhao, L. and Hosseini, M.R. (2021), "BIM adoption in the Cambodian construction industry: key drivers and barriers", ISPRS International Journal of Geo-Information, Vol. 10 No. 4, p. 215.

Eadie, R., Browne, M., Odeyinka, H., McKeown, C. and McNiff, S. (2013), "BIM implementation throughout the UK construction project lifecycle: an analysis", Automation in Construction, Vol. 36, pp. 145-151.

Eastman, C.M. and Siabiris, A. (1995), "A generic building product model incorporating building type information", Automation in Construction, Vol. 3 No. 4, pp. 283-304.

Eastman, C.M., Eastman, C., Teicholz, P., Sacks, R. and Liston, K. (2008), "BIM handbook: a guide to building information modeling for owners, managers", Designers, Engineers and Contractors, Wiley, available at: https://books.google.fi/books?id=IioygNOnYzMC.

Elhariri Essamlali, M.T., Sekhari, A. and Bouras, A. (2016), "PLM system support for collaborative development of wearable meta-products using SBCE", in Bouras, A., Eynard, B., Foufou, S. and Thoben, K.-D. (Eds), Product Lifecycle Management in the Era of Internet of Things, Vol. 467, Springer International Publishing, Cham, pp. 33-42.

Farrugia, B. (2019), “WASP (write a scientific paper): sampling in qualitative research”, Early Human Development, Vol. 133, pp. 69-71.

Fu, C., Aouad, G., Lee, A., Mashall-Ponting, A. and Wu, S. (2006), "IFC model viewer to support nD model application”, Automation in Construction, Vol. 15 No. 2, pp. 178-185.
Productization and product structure

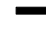


Gardezi, S.S.S., Shafiq, N., Nuruddin, M.F., Farhan, S.A. and Umar, U.A. (2014), "Challenges for implementation of building information modeling (BIM) in Malaysian construction industry", Presented at the Structural, Environmental, Coastal and Offshore Engineering, Vol. 567, Trans Tech Publications, Applied Mechanics and Materials, pp. 559-564.

Garwood, D. (1997), Bills of Material: Structured for Excellence, Dogwood Publishing Company, Marietta, GA.

Gasparyan, A.Y., Ayvazyan, L. and Kitas, G.D. (2013), "Multidisciplinary bibliographic databases", Journal of Korean Medical Science, The Korean Academy of Medical Sciences, Vol. 28 No. 9, pp. 1270-1275.

Gerges, M., Austin, S., Mayouf, M., Ahiakwo, O., Jaeger, M., Saad, A. and El Gohary, T. (2017), "An investigation into the implementation of building information modeling in the Middle East", Journal of Information Technology in Construction, Vol. 22, pp. 1-15.

Ghaffarianhoseini, A., Tookey, J., Ghaffarianhoseini, A., Naismith, N., Azhar, S., Efimova, O. and Raahemifar, K. (2017), "Building Information Modelling (BIM) uptake: clear benefits, understanding its implementation, risks and challenges", Renewable and Sustainable Energy Reviews, Vol. 75, pp. 1046-1053.

Gioia, D.A., Corley, K.G. and Hamilton, A.L. (2013), "Seeking qualitative rigor in inductive research: notes on the Gioia methodology”, Organizational Research Methods, Vol. 16 No. 1, pp. 15-31.

Gunzenhauser, M. and Bongulielmi, L. (2007), "Global product structure matrix: an integrated component of a variable process model for global platforms", Presented at the International Conference on Engineering Design, ICED’ 07, Paris, France, pp. 1-12.

Guvendiren, K., Brinkkemper, S. and Jansen, S. (2014), "Productization of an IT service firm", LNPIB, Presented at the 5th International Conference on Software Business, Paphos, Cyprus, Vol. 182, pp. 115-131.

Hall, D.M., Whyte, J.K. and Lessing, J. (2020), "Mirror-breaking strategies to enable digital manufacturing in Silicon Valley construction firms: a comparative case study", Construction Management and Economics, Vol. 38 No. 4, pp. 322-339.

Halttula, H. (2020), "Enhancing data utilisation in the construction project lifecycle through early involvement and integration", $\mathrm{PhD}$ Thesis, University of Oulu, Oulu, available at: http://jultika. oulu.fi/files/isbn9789526226156.pdf.

Hamidavi, T., Abrishami, S. and Hosseini, M.R. (2020), "Towards intelligent structural design of buildings: a BIM-based solution”, Journal of Building Engineering, Vol. 32, doi: 10.1016/j.jobe. 2020.101685 .

Handford, M. and Koester, A. (2019), "The construction of conflict talk across workplace contexts: (towards) a theory of conflictual compact”, Language Awareness, Vol. 28 No. 3, pp. 186-206.

Hannila, H., Koskinen, J., Harkonen, J. and Haapasalo, H. (2019), "Product-level profitability: current challenges and preconditions for data-driven, fact-based product portfolio management", Journal of Enterprise Information Management, Vol. 33 No. 1, pp. 214-237.

Harkonen, J. (2021), "Exploring the benefits of service productization: support for business processes", Business Process Management Journal, Vol. 27 No. 8, pp. 85-105.

Harkonen, J., Haapasalo, H. and Hanninen, K. (2015), "Productisation: a review and research agenda", International Journal of Production Economics, Vol. 164, pp. 65-82.

Harkonen, J., Tolonen, A. and Haapasalo, H. (2017), "Service productisation: systematising and defining an offering", Journal of Service Management, Vol. 28 No. 5, pp. 936-971.

Harkonen, J., Tolonen, A. and Haapasalo, H. (2018), "Modelling of construction products and services for effective productisation", Management, Vol. 13 No. 4, pp. 335-353.

Harkonen, J., Mustonen, E. and Haapasalo, H. (2019a), "Construction related data managementclassification and description of data from different perspectives", Presented at the Management, Knowledge and Learning International Conference, (MakeLearn), Piran, Slovenia. 
Harkonen, J., Mustonen, E. and Hannila, H. (2019b), "Productization and product structure as the backbone for product data and fact-based analysis of company products", Presented at the IEEE International Conference on Industrial Engineering and Engineering Management, pp. $474-478$.

Heimes, H.H., Kampker, A., Haunreiter, A., Davids, H. and Klohs, D. (2020), "Product-requirementmodel to approach the identification of uncertainties in battery systems development", International Journal on Interactive Design and Manufacturing (IJIDeM), Vol. 14 No. 3, pp. 911-922.

Heravi, G., Kebria, M.F. and Rostami, M. (2019), "Integrating the production and the erection processes of pre-fabricated steel frames in building projects using phased lean management", Engineering, Construction and Architectural Management, Vol. 28 No. 1, pp. 174-195.

Heusinkveld, S. and Benders, J. (2005), "Contested commodification: consultancies and their struggle with new concept development", Human Relations, Vol. 58 No. 3, pp. 283-310.

Holle, M. and Lindemann, U. (2014), "Design for Open Innovation (DfOI); Product structure planning for open innovation toolkits", Presented at the International Conference on Industrial Engineering and Engineering Management, IEEE, Selangor Darul Ehsan, Malaysia, pp. 536-540.

Holzer, D. (2014), "Fostering the link from PLM to ERP via BIM: the AEC industry in transition", in Fukuda, S., Bernard, A., Gurumoorthy, B. and Bouras, A. (Eds), Product Lifecycle Management for a Global Market, Vol. 442, Springer Berlin Heidelberg, Berlin, Heidelberg, pp. 75-82.

Jia, S., Liu, C., Guan, X., Wu, H., Zeng, D. and Guo, J. (2022), "Bidirectional interaction between BIM and construction processes using a multisource geospatial data enabled point cloud model", Automation in Construction, Vol. 134, p. 104096.

Jupp, J.R. (2016), “Cross industry learning: a comparative study of product lifecycle management and building information modelling", International Journal of Product Lifecycle Management, Vol. 9 No. 3, p. 258.

Jupp, J.R. and Nepal, M. (2014), "BIM and PLM: comparing and learning from changes to professional practice across sectors", in Fukuda, S., Bernard, A., Gurumoorthy, B. and Bouras, A. (Eds), Product Lifecycle Management for a Global Market, Vol. 442, Springer, Berlin, Heidelberg, pp. 41-50.

Kaner, I., Sacks, R., Kassian, W. and Quitt, T. (2008), "Case studies of BIM adoption for precast concrete design by mid-sized structural engineering firms", Journal of Information Technology in Construction (ITcon), Vol. 13 No. 21, pp. 303-323.

Kankaanpaa, I. and Isomaki, H. (2013), "Productization and commercialization of it-enabled higher education in computer science: a systematic literature review", Proceedings of the International Conference E-Learning, pp. 41-48.

Koskela, L. (2000), "An exploration towards a production theory and its application to construction", Doctoral Dissertation, Technical Research Centre of Finland, Espoo, available at: https:// aaltodoc.aalto.fi/bitstream/handle/123456789/2150/isbn951385566x.pdf?sequence=1.

Küchenhof, J. and Krause, D. (2020), "Initial integral product and assembly structuring: a case study", Proceedings of the Design Society: DESIGN Conference, Vol. 1, pp. 2305-2314.

Kuula, S., Haapasalo, H. and Tolonen, A. (2018), "Cost-efficient co-creation of knowledge intensive business services”, Service Business, Vol. 12 No. 4, pp. 779-808.

Lahtinen, N., Mustonen, E. and Harkonen, J. (2021), "Commercial and technical productization for factbased product portfolio management over lifecycle", IEEE Transactions on Engineering Management, Vol. 68 No. 6, pp. 1826-1838.

Leenen, W., Vlaanderen, K., van de Weerd, I. and Brinkkemper, S. (2012), "Transforming to product software: the evolution of software product management processes during the stages of productization", in Cusumano, M.A., Iyer, B. and Venkatraman, N. (Eds), Software Business, Vol. 114, Springer Berlin Heidelberg, Berlin, Heidelberg, pp. 40-54.
Productization and product structure 
Lehtovaara, J., Seppänen, O., Peltokorpi, A., Kujansuu, P. and Grönvall, M. (2021), "How takt production contributes to construction production flow: a theoretical model", Construction Management and Economics, Vol. 39 No. 1, pp. 73-95.

Li, N.-Y., Zhang, J. and Liu, D.-Y. (2010), "Product configuration based on generic product structure", Jisuanji Jicheng Zhizao Xitong/Computer Integrated Manufacturing Systems, CIMS, Vol. 16 No. 1, pp. 17-23.

Li, J., Yang, W., Zhang, Y., Pei, Y., Ren, Y. and Wang, W. (2013), “Aircraft vulnerability modeling and computation methods based on product structure and CATIA", Chinese Journal of Aeronautics, Vol. 26 No. 2, pp. 334-342.

Li, L., Yuan, J., Tang, M., Xu, Z., Xu, W. and Cheng, Y. (2021), "Developing a BIM-enabled building lifecycle management system for owners: architecture and case scenario", Automation in Construction, Vol. 129, doi: 10.1016/j.autcon.2021.103814.

Liang, K., Fan, D., Tang, L., Cao, Y. and Zheng, K. (2010), "VPDM-based product structure data exchange", International Conference On Computer Design and Applications, Qinhuangdao, China, pp. V2-255-V2-258.

Liu, X. and Wang, K. (2013), “A bom generation algorithm of erp”, Presented at the 2013 IEEE 3rd International Conference on Information Science and Technology, ICIST, 2013, pp. 681-684.

Liu, G., Man, R. and Wang, Y. (2021), "A data management approach based on product morphology in product lifecycle management", Processes, Vol. 9 No. 7, p. 1235.

Lu, N.Y., Liu, F.Y. and Shay, T. (2011), "A product structure management method based on Ajax", Advanced Materials Research, Vols 201-203, pp. 744-749.

Luo, T., Xue, X., Tan, Y., Wang, Y. and Zhang, Y. (2020), "Exploring a body of knowledge for promoting the sustainable transition to prefabricated construction", Engineering, Construction and Architectural Management, Vol. 28 No. 9, pp. 2637-2666.

Ma, X., Chan, A.P.C., Li, Y., Zhang, B. and Xiong, F. (2020), "Critical strategies for enhancing BIM implementation in AEC projects: perspectives from Chinese practitioners", Journal of Construction Engineering and Management, Vol. 146 No. 2, p. 05019019.

Magnusson, M. and Pasche, M. (2014), “A contingency-based approach to the use of product platforms and modules in new product development", Journal of Product Innovation Management, Vol. 31 No. 3, pp. 434-450.

Mannisto, T., Peltonen, H., Martio, A. and Sulonen, R. (1998), "Modelling generic product structures in STEP”, Computer-Aided Design, Vol. 30 No. 14, pp. 1111-1118.

Maraqa, M.J., Sacks, R. and Spatari, S. (2021), "Quantitative assessment of the impacts of BIM and lean on process and operations flow in construction projects", Engineering, Construction and Architectural Management, Vol. 28 No. 8, pp. 2176-2198.

Marshall, M.N. (1996), “Sampling for qualitative research”, Family Practice, Vol. 13 No. 6, pp. 522-526.

Marzouk, M. and Othman, A. (2020), "Planning utility infrastructure requirements for smart cities using the integration between BIM and GIS”, Sustainable Cities and Society, Vol. 57, p. 102120.

Mason, J. (2004), "Semistructured interview", The SAGE Encyclopedia of Social Science Research Methods, 2nd ed.

McGraw-Hill Construction (2012), The Business Value of BIM in North America: Multi-Year Trend Analysis and User Ratings (2007-2012), SmartMarket Report, McGraw-Hill Construction, New York, available at: https://damassets.autodesk.net/content/dam/autodesk/www/ solutions/building-information-modeling/bim-value/mhc-business-value-of-bim-in-northamerica.pdf.

Meng, Q., Zhang, Y., Li, Z., Shi, W., Wang, J., Sun, Y., Xu, L. and Wang, X. (2020), "A review of integrated applications of BIM and related technologies in whole building life cycle", Engineering, Construction and Architectural Management, Vol. 27 No. 8, pp. 1647-1677. 
Mörschel, I., Behrens, H., Fähnrich, K.-P. and Elze, R. (2007), "Standardisation in the service sector for global markets", in Spath, D. and Fähnrich, K.P. (Eds), Advances in Services Innovations, Springer, Berlin, Heidelberg, pp. 257-277.

NBS (2016), International BIM Report 2016, RIBA Enterprises, Newcastle upon Tyne.

Neff, G., Fiore-Silfvast, B. and Dossick, C.S. (2010), "A case study of the failure of digital communication to cross knowledge boundaries in virtual construction", Information, Communication and Society, Vol. 13 No. 4, pp. 556-573.

Ng, M.S., Bonanomi, M.M., Hall, D.M. and Hackl, J. (2020), "Design for digital fabrication: an industry needs analysis of collaboration platforms and integrated management processes", Presented at the Proceedings of the 37th International Symposium on Automation and Robotics in Construction, ISARC 2020: From Demonstration to Practical Use - to New Stage of Construction Robot, pp. 318-325.

Olanrewaju, O.I., Chileshe, N., Babarinde, S.A. and Sandanayake, M. (2020), "Investigating the barriers to building information modeling (BIM) implementation within the Nigerian construction industry", Engineering, Construction and Architectural Management, Emerald Publishing, Vol. 27 No. 10, pp. 2931-2958.

Oraee, M., Hosseini, M.R., Edwards, D.J., Li, H., Papadonikolaki, E. and Cao, D. (2019), “Collaboration barriers in BIM-based construction networks: a conceptual model", International Journal of Project Management, Vol. 37 No. 6, pp. 839-854.

Park, S., Ju, S., Yoon, S., Nguyen, M.H. and Heo, J. (2021), “An efficient data structure approach for BIM-to-point-cloud change detection using modifiable nested octree", Automation in Construction, Vol. 132, p. 103922.

Patacas, J., Dawood, N., Vukovic, V. and Kassem, M. (2015), "BIM for facilities management: evaluating BIM standards in asset register creation and service life planning", Journal of Information Technology in Construction, Vol. 20, pp. 313-331.

Pauwels, P., Zhang, S. and Lee, Y.-C. (2017), "Semantic web technologies in AEC industry: a literature overview", Automation in Construction, Vol. 73, pp. 145-165.

Pinquié, R., Rivest, L., Segonds, F. and Véron, P. (2015), "An illustrated glossary of ambiguous PLM terms used in discrete manufacturing", International Journal of Product Lifecycle Management, Vol. 8 No. 2, p. 142.

Pourzarei, H., Rivest, L. and Boton, C. (2020), "Cross-pollination as a comparative analysis approach to comparing BIM and PLM: a literature review", in Nyffenegger, F., Ríos, J., Rivest, L. and Bouras, A. (Eds), Product Lifecycle Management Enabling Smart X, Vol. 594, Springer International Publishing, Cham, pp. 724-737.

Pyron, C., Prado, J. and Golab, J. (1998), “Test strategy for the PowerPC 750 microprocessor”, IEEE Design and Test of Computers, Vol. 15 No. 3, pp. 90-97.

Radl, J. and Kaiser, J. (2019), "Benefits of implementation of common data environment (CDE) into construction projects", IOP Conference Series: Materials Science and Engineering, Vol. 471, p. 022021.

Razali, M.F., Haron, N.A., Hassim, S., Alias, A.H., Harun, A.N. and Abubakar, A.S. (2019), "A review: application of building information modelling (BIM) over building life cycles", IOP Conference Series: Earth and Environmental Science, IOP Publishing, Vol. 357 No. 1, p. 012028.

RICS (2015), BIM for Cost Managers: Requirements from the BIM Model, Professional Guidance, Royal Institution of Chartered Surveyors, London, available at: https://www.rics.org/globalassets/ricswebsite/media/upholding-professional-standards/sector-standards/construction/bim-for-costmanagers-1st-edition-rics.pdf.

Riesener, M., Dölle, C., Schuh, G., Mendl-Heinisch, M. and Keuper, A. (2020), "Derivation of starting solutions based on product architecture flexibility evaluation", Proceedings of the Design Society: DESIGN Conference, Vol. 1, pp. 1077-1086.
Productization and product structure

(1)


Rocco, T.S. (2003), "Qualitative research interviewing: biographic narrative and semi-structured methods”, Human Resource Development Quarterly, Vol. 14 No. 1, pp. 117-122.

Saaksvuori, A. and Immonen, A. (2008), Product Lifecycle Management, Springer, Berlin, Heidelberg, doi: 10.1007/978-3-540-78172-1.

Sarinko, K., Bjorkstrand, R. and Martio, A. (2005), "An empirical study of requirements related to generic product structures in CAD-PDM integration", Presented at the ICED 05: 15th International Conference on Engineering Design: Engineering Design and the Global Economy, Melbourne, Australia.

Sbiti, M., Beddiar, K., Beladjine, D., Perrault, R. and Mazari, B. (2021), "Toward BIM and LPS data integration for lean site project management: a state-of-the-art review and recommendations", Buildings, Vol. 11 No. 5, doi: 10.3390/buildings11050196.

Schiavi, B., Havard, V., Beddiar, K. and Baudry, D. (2022), "BIM data flow architecture with AR/VR technologies: use cases in architecture, engineering and construction", Automation in Construction, Vol. 134, doi: 10.1016/j.autcon.2021.104054.

Schimanski, C.P., Marcher, C., Monizza, G.P. and Matt, D.T.(2020), "The last planner ${ }^{\circledR}$ system and building information modeling in construction execution: from an integrative review to a conceptual model for integration”, Applied Sciences (Switzerland), Vol. 10 No. 3, doi: 10.3390/app10030821.

Şenaltun, G. and Cangelir, C. (2013), "DMU management - product structure and master geometry correlation", Presented at the 20th ISPE International Conference on Concurrent Engineering, IOS Press, pp. 353-360.

Sharif, M.M., Haas, C. and Walbridge, S. (2022), "Using termination points and 3D visualization for dimensional control in prefabrication”, Automation in Construction, Vol. 133, doi: 10.1016/j. autcon.2021.103998.

Shih, H.M. (2014), "Migrating product structure bill of materials Excel files to STEP PDM implementation”, International Journal of Information Management, Vol. 34 No. 4, pp. 489-516.

Shirowzhan, S., Sepasgozar, S.M.E., Edwards, D.J., Li, H. and Wang, C. (2020), "BIM compatibility and its differentiation with interoperability challenges as an innovation factor", Automation in Construction, Vol. 112, p. 103086.

Simula, H., Lehtimäki, T. and Salo, J. (2008), "Re-thinking the product - from innovative technology to productized offering", Proceedings of the 19th International Society for Professional Innovation Management Conference, Tours, France.

Singh, V., Gu, N. and Wang, X. (2011), "A theoretical framework of a BIM-based multi-disciplinary collaboration platform", Automation in Construction, Vol. 20 No. 2, pp. 134-144.

Son, H., Lee, S. and Kim, C. (2015), "What drives the adoption of building information modeling in design organizations? An empirical investigation of the antecedents affecting architects' behavioral intentions", Automation in Construction, Vol. 49, pp. 92-99.

Stoyanova, M. (2020), "Good practices and recommendations for success in construction digitalization", TEM Journal, UIKTEN - Association for Information Communication Technology Education and Science, Vol. 9 No. 1, pp. 42-47.

Succar, B. (2010), "Building information modelling maturity matrix", Handbook of Research on Building Information Modeling and Construction Informatics: Concepts and Technologies, IGI Global, pp. 65-103.

Sun, C., Jiang, S., Skibniewski, M.J., Man, Q. and Shen, L. (2017), "A literature review of the factors limiting the application of BIM in the construction industry", Technological and Economic Development of Economy, Taylor \& Francis, Vol. 23 No. 5, pp. 764-779.

Suominen, A., Kantola, J. and Tuominen, A. (2009), "Reviewing and defining productization", 20th Annual Conference of the International Society for Professional Innovation Management (ISPIM), available at: https://www.researchgate.net/profile/Arho_Suominen/publication/ 236326445_Reviewing_and_Defining_Productization/links/5656c32108aeafc2aac09552/ Reviewing-and-Defining-Productization.pdf. 
Tang, S., Shelden, D.R., Eastman, C.M., Pishdad-Bozorgi, P. and Gao, X. (2020), "BIM assisted Building Automation System information exchange using BACnet and IFC", Automation in Construction, Vol. 110, p. 103049.

Tekin, E. (2014), "A method for traceability and 'as-built product structure' in aerospace industry", Procedia CIRP, Vol. 17, pp. 351-355.

Terreno, S., Asadi, S. and Anumba, C. (2019), "An exploration of synergies between lean concepts and BIM in FM: a review and directions for future research", Buildings, Multidisciplinary Digital Publishing Institute, Vol. 9 No. 6, p. 147.

Thomé, A.M.T., Scavarda, L.F. and Scavarda, A.J. (2016), "Conducting systematic literature review in operations management”, Production Planning and Control, Vol. 27 No. 5, pp. 408-420.

Tichem, M. and Storm, T. (1997), "Designer support for product structuring-development of a DFX tool within the design coordination framework", Computers in Industry, Vol. 33 Nos 2-3, pp. 155-163.

Tolonen, A., Harkonen, J. and Haapasalo, H. (2014), "Product portfolio management-governance for commercial and technical portfolios over life cycle", Technology and Investment, Vol. 5 No. 4, pp. 173-183.

Tolonen, A., Harkonen, J., Verkasalo, M. and Haapasalo, H. (2015), "Product portfolio management process over horizontal and vertical portfolios", International Journal of Product Lifecycle Management, Vol. 8 No. 3, pp. 189-215.

Torregrosa-Jaime, B., González, B., Martínez, P. and Payá-Ballester, G. (2018), "Analysis of the operation of an aerothermal heat pump in a residential building using building information modelling”, Energies, Vol. 11 No. 7, p. 1642.

UniFormat (2010), UniFormat ${ }^{T M}$ : A Uniform Classification of Construction Systems and Assemblies, Standard, Constructions Specification Institute (CSI)/Construction Specifications Canada (CSC), Toronto, Ontario, p. 196.

Valminen, K. and Toivonen, M. (2012), "Seeking efficiency through productisation: a case study of small KIBS participating in a productisation project", The Service Industries Journal, Vol. 32 No. 2, pp. 273-289.

Valtakoski, A. and Järvi, K. (2016), "Productization of knowledge-intensive services: enabling knowledge sharing and cross-unit collaboration”, Journal of Service Management, Vol. 27 No. 3, pp. 360-390.

Venkatesh, R. (2015), "Fusion product structure of demazure modules", Algebras and Representation Theory, Vol. 18 No. 2, pp. 307-321.

Wei, P., Zhao, J., Yang, X., Zhang, L. and He, W. (2019), "Multidimensional data management system for spacecraft AIT process based on product structure", Presented at the IOP Conference Series: Materials Science and Engineering, Vol. 612, doi: 10.1088/1757-899X/612/3/ 032128 .

Wen, Q.J., Ren, Z.-J., Lu, H. and Wu, J.F. (2021), "The progress and trend of BIM research: a bibliometrics-based visualization analysis", Automation in Construction, Vol. 124, p. 103558.

Wilson, J. (2010), Essentials of Business Research: A Guide to Doing Your Research Project, SAGE Publications, London.

Windheim, M., Greve, E. and Krause, D. (2017), "Decisive economies and opportunity cost of modular product structure alternatives: an empirical case study", International Conference on Industrial Engineering and Engineering Management (IEEM), Singapore, pp. 1636-1640.

Wirtz, J., Fritze, M.P., Jaakkola, E., Gelbrich, K. and Hartley, N. (2021), "Service products and productization”, Journal of Business Research, Vol. 137, pp. 411-421.

Wu, Y. and Kimura, F. (2007), "Conceptual design of product structure for parts reuse", in Takata, S. and Umeda, Y. (Eds), Advances in Life Cycle Engineering for Sustainable Manufacturing Businesses, Springer London, London, pp. 35-40.
Productization and product structure 
Zhang, X., Li, L., Lyu, X. and Li, X. (2017), "Network data envelopment analysis with intermediate products structure", Advances in Engineering Research, Presented at the Proceedings of Advances in Materials, Machinery, Electrical Engineering (AMMEE 2017), Vol. 114, Tianjin, China, available at::file://C:/Users/smansoor/AppData/Local/Temp/25878431.pdf.

Zhang, Y., Zhang, N. and Sun, L. (2017), "Research on the method in aerospace computer productization", 6th International Conference on Industrial Technology and Management (ICITM), Cambridge, United Kingdom, pp. 114-117.

Zuppa, D., Issa, R.R. and Suermann, P.C. (2009), "BIM's impact on the success measures of construction projects”, Computing in Civil Engineering, Vol. 1 (Supp. ASCE Book Series), pp. 503-512.

\section{Appendix}

\begin{tabular}{|c|c|c|}
\hline Theme & Main questions & In view of \\
\hline \multirow[t]{12}{*}{ Productization } & 1- How do you define product? & \multirow{9}{*}{$\begin{array}{l}\text { - in construction } \\
\text { - in your company } \\
\text { - in your company } \\
\text { - Content } \\
\text { - method } \\
\text { - Process } \\
\text { - Practices } \\
\text { - Outcomes } \\
\text { - Challenges } \\
\text { - Capacity to make } \\
\text { (technical side) } \\
\text { - Capacity to sell } \\
\text { (commercial side) }\end{array}$} \\
\hline & 2- How do you define product development? & \\
\hline & 3- How you define productization in construction project? & \\
\hline & & \\
\hline & & \\
\hline & & \\
\hline & & \\
\hline & $\begin{array}{l}\text { 4- What are challenges in product development journey and } \\
\text { those for improving product value for customers moving from a }\end{array}$ & \\
\hline & core product into extended product? & \\
\hline & 5- How does productization suffer from lack of centralised & - Content \\
\hline & product/process information? & - Process \\
\hline & & - Outcomes \\
\hline Your ideas & $\begin{array}{l}\text { 6- Are there anything else that you think we should know to } \\
\text { facilitate productization and information flow? }\end{array}$ & \\
\hline
\end{tabular}

Table A1. Interview questionnaire

\section{Corresponding author}

Janne Harkonen can be contacted at: Janne.Harkonen@oulu.fi

For instructions on how to order reprints of this article, please visit our website:

www.emeraldgrouppublishing.com/licensing/reprints.htm

Or contact us for further details: permissions@emeraldinsight.com 